Supporting Information for:

\title{
Nickel(II) Metal Complexes as Optically Addressable Qubit Candidates
}

Michael K. Wojnar, ${ }^{1}$ Daniel W. Laorenza, ${ }^{1}$ Richard D. Schaller, ${ }^{1,2}$ Danna E. Freedman ${ }^{1 *}$

1. Department of Chemistry, Northwestern University, Evanston, Illinois 60208

2. Center for Nanoscale Materials, Argonne National Laboratory, Lemont, Illinois 60439 


\section{Table of Contents}

$\begin{array}{lc}\text { Full Experimental Details } & \text { S3 }\end{array}$

Table S1 | Summary of crystallographic data for $\mathbf{1}$

Table S2 | Summary of crystallographic data for $\mathbf{2} \quad$ S6

$\begin{array}{ll}\text { Table S3 } \mid T_{\mathrm{m}} \text { and } T_{1} \text { data for } \mathbf{1} & \mathbf{S 7}\end{array}$

$\begin{array}{ll}\text { Table S4 } \mid T_{\mathrm{m}} \text { and } T_{1} \text { data for } \mathbf{2} & \mathbf{S 8}\end{array}$

Table S5 | Spin Hamiltonian parameters for 1 and 2

$\begin{array}{ll}\text { Figure S1 | Crystal structures of } \mathbf{1} \text { and } \mathbf{2} & \mathbf{S 1 0}\end{array}$

$\begin{array}{ll}\text { Figure S2 } \mid 100 \mathrm{~K} \text { variable-field magnetization of } \mathbf{1} \text { and } \mathbf{2} & \mathbf{S 1 1}\end{array}$

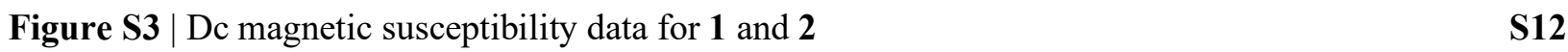

Figure S4 | Variable-temperature, variable-field magnetization data for $\mathbf{1}$ and $\mathbf{2} \quad \mathbf{S 1 3}$

$\begin{array}{lc}\text { Figure S5 | High-frequency cw-EPR spectra of } 1 & \text { S14 }\end{array}$

Figure S6 | Zeeman diagrams for 318.7 GHz EPR transitions for 1 $\quad$ S15

Figure S7 | High-frequency cw-EPR spectra of $2 \quad \mathbf{S 1 6}$

$\begin{array}{ll}\text { Figure S8 } \mid \text { Zeeman diagrams for } 320.9 \mathrm{GHz} \text { EPR transitions for } \mathbf{2} & \text { S17 }\end{array}$

Figure S9 | Simulated echo-detected field-sweep of $\mathbf{1}$ and $\mathbf{2}$ at W-band frequency $\quad$ S18

Figure S10 | Experimental echo-detected field-sweep of $\mathbf{1}$ and $\mathbf{2}$ at W-band frequency $\quad \mathbf{S 1 9}$

Figure S11 | Variable temperature Hahn-echo decay curves and fits for 1 at $1.53 \mathrm{~T} \quad \mathbf{S 2 0}$

$\begin{array}{ll}\text { Figure S12 | Saturation-recovery data for } 1 \text { at } 1.53 \mathrm{~T} & \text { S21 }\end{array}$

Figure S13 | Variable temperature Hahn-echo decay curves and fits for 1 at $3.00 \mathrm{~T} \quad \mathbf{S 2 2}$

$\begin{array}{ll}\text { Figure S14 | Saturation-recovery data for } 1 \text { at } 3.00 \mathrm{~T} & \mathbf{S 2 3}\end{array}$

Figure S15 | Variable temperature Hahn-echo decay curves and fits for 2 at $0.00 \mathrm{~T} \quad \mathbf{S 2 4}$

$\begin{array}{ll}\text { Figure S16 | Saturation-recovery data for } 2 \text { at } 0.00 \mathrm{~T} & \text { S25 }\end{array}$

Figure S17 | Variable temperature Hahn-echo decay curves and fits for 2 at $0.69 \mathrm{~T} \quad \mathbf{S 2 6}$

$\begin{array}{ll}\text { Figure S18 | Saturation-recovery data for } 2 \text { at } 0.69 \mathrm{~T} & \text { S27 }\end{array}$

Figure S19 | Variable temperature Hahn-echo decay curves and fits for 2 at $3.00 \mathrm{~T} \quad$ S28

$\begin{array}{ll}\text { Figure S20 | Saturation-recovery data for } 2 \text { at } 3.00 \mathrm{~T} & \text { S29 }\end{array}$

Figure S21 | Variable temperature Hahn-echo decay curves and fits for 2 at $6.00 \mathrm{~T} \quad \mathbf{S 3 0}$

$\begin{array}{ll}\text { Figure S22 | Saturation-recovery data for } 2 \text { at } 6.00 \mathrm{~T} & \text { S31 }\end{array}$

Figure $\mathbf{S 2 3} \mid T_{1}$ and $T_{\mathrm{m}}$ values for $\mathbf{2} \quad \mathbf{S 3 2}$

Figure S24 | Electronic absorption (UV-vis-NIR) spectra for $\mathbf{1}$ and $\mathbf{2} \quad \mathbf{S 3 2}$

$\begin{array}{ll}\text { Figure S25 | Photoluminescence spectra for } 1 & \text { S34 }\end{array}$

$\begin{array}{ll}\text { Figure S26 | Photoluminescence spectra for } 2 & \mathbf{S 3 5}\end{array}$

References $\quad$ S36 


\section{Experimental Details.}

General Considerations. Glassware was either oven-dried at $150{ }^{\circ} \mathrm{C}$ for at least 4 hours or flame-dried prior to use. Acetonitrile $(\mathrm{MeCN})$ and diethylether $\left(\mathrm{Et}_{2} \mathrm{O}\right)$ were dried using a commercial solvent purification system from Pure Process Technology and stored over 3 or $4 \AA$ sieves prior to use. Tris-2pyridyl-methane was prepared by the literature methods. ${ }^{1} \mathbf{1}$ and $\mathbf{2}$ were prepared by minor variation of literature procedures. ${ }^{2,3}$ All other chemicals were used as received.

[Ni(phen) $\left.)_{3}\right]\left(\mathbf{B F}_{4}\right)_{2}(\mathbf{1})$. We added a green solution of $\left[\mathrm{Ni}\left(\mathrm{H}_{2} \mathrm{O}\right)_{6}\right]\left(\mathrm{BF}_{4}\right)_{2}(214 \mathrm{mg}, 0.63 \mathrm{mmol}, 1.00$ equiv. $)$ in acetonitrile $(3 \mathrm{~mL})$ to a stirring clear solution of 1,10-phenanthroline (352 mg, $1.95 \mathrm{mmol}, 3.10$ equiv.) in acetonitrile $(3 \mathrm{~mL})$ to immediately yield a vibrant red-pink solution. The solution was stirred for 1 hour at room temperature, then layered under diethyl ether $(10 \mathrm{~mL})$ to yield large red-pink blocks after slow diffusion of the two layers overnight (452 mg, 91\%). UV-vis (MeCN); $v_{\max }\left(\varepsilon_{\mathrm{M}}, \mathrm{M}^{-1} \mathrm{~cm}^{-1}\right)$ : $522(16) \mathrm{nm}$; 786 (9) nm. ESI/MS (m/z): [Ni(phen $\left.)_{3}\right]\left(\mathrm{BF}_{4}\right)^{+}, 685.120$.

$\left[\mathbf{N i}\left(\mathbf{p y r}_{3}\right)_{2}\right]\left(\mathbf{B F}_{4}\right)_{2}(\mathbf{2})$. We added a green solution of $\left[\mathrm{Ni}\left(\mathrm{H}_{2} \mathrm{O}\right)_{6}\right]\left(\mathrm{BF}_{4}\right)_{2}(235 \mathrm{mg}, 0.69 \mathrm{mmol}, 1.00$ equiv. $)$ in acetonitrile $(3 \mathrm{~mL})$ to a stirring clear solution of tris-2-pyridyl-methane (358 $\mathrm{mg}, 1.45 \mathrm{mmol}, 2.10$ equiv.) in acetonitrile $(3 \mathrm{~mL})$ to immediately yield a vibrant orange solution. The solution was stirred for 2 hours at room temperature, then layered under diethyl ether $(10 \mathrm{~mL})$ to yield large orange blocks after slow diffusion of the two layers overnight (401 mg, 80\%). UV-vis (MeCN); $v_{\max }\left(\varepsilon_{\mathrm{M}}, \mathrm{M}^{-1} \mathrm{~cm}^{-1}\right)$ : $438(356) \mathrm{nm}$; 770 (9) nm. ESI/MS (m/z): [Ni(phen $\left.)_{3}\right]\left(\mathrm{BF}_{4}\right)^{+}, 640.105$.

Magnetic Measurements. Magnetic data were acquired on a Quantum Design MPMS-XL SQUID magnetometer. Measurements for $\mathbf{1}$ and $\mathbf{2}$ were obtained on finely ground microcrystalline powders restrained in a frozen eicosane matrix and wrapped tightly within a gel cap. Dc susceptibility measurements were collected in the temperature range of $1.8-300 \mathrm{~K}$ at a dc field of 5000 Oe. Magnetization measurements were obtained in the temperature range $1.8-10 \mathrm{~K}$ under dc fields of $1,2,3,4,5,6$, and $7 \mathrm{~T}$. Dc magnetic susceptibility data were corrected for diamagnetic contributions from the sample holder and eicosane as well as for the core diamagnetism of each sample, estimated using Pascal's constants. ${ }^{4}$ Prior to full characterization, magnetization data were acquired at $100 \mathrm{~K}$ from 0 to $4 \mathrm{~T}$ to ensure the absence of curvature associated with ferromagnetic impurities.

X-ray Diffraction. Single crystal X-ray diffraction data were acquired on single crystals coated with Paratone-N oil and mounted on a MicroMounts ${ }^{\mathrm{TM}}$ rod. The crystals were frozen under a stream of $\mathrm{N}_{2}$ during measurements. Data were collected with a Bruker MICROSTAR X-ray source of Mo $\operatorname{Ka}(\lambda=0.71073 \AA)$ radiation and a Bruker APEX-II detector. Raw data were integrated and corrected for Lorentz and polarization effects using Bruker Apex2 v. 2013.2. ${ }^{5}$ Absorption corrections were applied using SADABS. ${ }^{6}$ 
Space group assignments were determined by examination of systematic absences, E-statistics, and successive refinement of the structures. The crystal structure was solved by direct methods with the aid of successive difference Fourier maps in SHELXL7 ${ }^{7}$ operated with the OLEX2 interface. ${ }^{8}$ The crystals did not show significant decay during data collection. Thermal parameters were refined anisotropically for all non-hydrogen atoms in the main body, solvents of crystallization, and counterions. Hydrogen atoms were placed in ideal positions and refined using a riding model for all structures.

EPR Measurements. All measurements were performed at the National High Magnetic Field Laboratory (NHMFL) in Tallahassee, Florida. High-frequency, high-field measurements were performed on finely ground powders restrained with eicosane. Samples were prepared in plastic caps or $4 \mathrm{~mm}$ O.D. quartz tubes (Wilmad) for measurement. High-field, high-frequency continuous-wave EPR (cw-EPR) spectra on $\mathbf{1}$ and 2 were collected on an instrument described elsewhere. ${ }^{9}$ Simulations of these spectra were carried out using the pepper function in Easyspin. ${ }^{10}$

Pulse EPR data were obtained at W-band frequency $(94 \mathrm{GHz})$ on HiPER at the NHMFL in Tallahassee, Florida. The architecture of the HiPER spectrometer can be found in the literature. ${ }^{11}$ Quasi-optical cw measurements were performed on HiPER using plastic sample holders. All pulse measurements were collected on $1.0 \mathrm{mM}$ frozen solutions in 1:1 (v/v) $\mathrm{H}_{2} \mathrm{O} /$ glycerol. Echo-detected field-swept EPR spectra were recorded using a two-pulse Hahn-echo sequence $(\pi / 2-\tau-\pi-\tau-$ echo) with microwave (mw) $\pi / 2$ and $\pi$ pulse lengths of $50 \mathrm{~ns}$ and $100 \mathrm{~ns}$, respectively, and an interpulse delay time $\tau=300 \mathrm{~ns}$. Hahn-echo decay curves were collected by application of the above sequence at the field of maximum echo intensity at variable temperatures using $50 \mathrm{~ns}$ and $100 \mathrm{~ns} \pi / 2$ and $\pi$ pulses, respectively, with varying $\tau$ (starting from $\tau$ $=300 \mathrm{~ns}$ ). All $T_{\mathrm{m}}$ decay curves were fit using the following exponential decay function, $I=A e^{-2 \tau / T_{m}}-I_{0}$, where $I_{0}$ is the initial intensity, $2 \tau$ is the interpulse delay time, and $T_{\mathrm{m}}$ is the phase memory time. Spinlattice relaxation times were measured at the same magnetic fields using a three-pulse saturation recovery sequence (long pulse $-\mathrm{T}-\pi / 2-\tau-\pi-\tau-$ echo) with $\tau$ of 300 ns chosen to minimize the effect of electron spin echo envelope modulation by surrounding nuclei.

Other Physical Measurements. Electrospray ionization mass spectrometry measurements (ESI-MS) were performed on MeCN solutions of $\mathbf{1}$ and $\mathbf{2}$ with Bruker AmaZon SL ESI-Ion Trap Mass Spectrometers at the IMSERC facility of Northwestern. Electronic absorption (UV-nis-NIR) spectra were collected for $\mathbf{1}$ and 2 in $\mathrm{MeCN}$ with a Varian Cary 5000 spectrophotometer. PL measurements were performed by exciting the samples with a $450 \mathrm{~nm}$ source. Powder samples of $\mathbf{1}$ and $\mathbf{2}$ were mounted onto sapphire slides in an evacuated Janis cryostat. 
Table S1 | Crystal data and structure refinement for 1.

\begin{tabular}{ll}
\hline Empirical formula & $\mathrm{C}_{38} \mathrm{H}_{27} \mathrm{~B}_{2} \mathrm{~F}_{8} \mathrm{~N}_{7} \mathrm{Ni}$ \\
Formula weight & 813.99 \\
Temperature & 100.11 \\
Wavelength & 0.71073 \\
Crystal system & Triclinic \\
Space group & $\mathrm{P}-1$ \\
Unit Cell Dimensions & $\mathrm{a}=11.2415(12) \AA, \alpha=102.499(4)^{\circ}$ \\
& $\mathrm{b}=11.8906(12) \AA, \beta=97.274(4)^{\circ}$ \\
& $\mathrm{c}=16.9548(18) \AA, \gamma=100.815(4)^{\circ}$ \\
Volume & $2140.0(4) \AA^{3}$ \\
$Z$ & 2 \\
Density (calculated) & 1.263 \\
Absorption coefficient & 0.522 \\
Fo00 & 828.0 \\
Crystal Color & $\mathrm{Pink}$ \\
Crystal size & $0.322 \times 0.294 \times 0.288 \mathrm{~mm}^{3}$ \\
$\theta$ range & 2.498 to $61.246^{\circ}$ \\
Index ranges & $-15 \leq h \leq 13$ \\
& $-17 \leq k \leq 16$ \\
Reflections collected & $-24 \leq l \leq 24$ \\
Independent reflections & 63490 \\
Completeness to $\theta=30.632^{\circ}$ & 12477 \\
Absorption correction & $94.5 \%$ \\
Maximum and minimum transmission & $\mathrm{Multi-scan}$ \\
Data/restraints/parameters & 0.7461 and 0.6549 \\
Goodness-of-fit on $\mathrm{F}^{2}$ & $12477 / 0 / 506$ \\
Final R indexes $[\mathrm{I}>=2 \sigma(\mathrm{I})]$ & 1.075 \\
Largest diff. peak and hole & $\mathrm{R}_{1}=7.08 \%, \mathrm{wR}_{2}=17.83 \%$ \\
& $\mathrm{R} 1=7.92 \%, \mathrm{wR} 2=18.28 \%$ \\
& 1.10 and $-0.99 \mathrm{e} . \AA^{-3}$ \\
\hline
\end{tabular}

${ }^{\mathrm{a}} G O F=\left[\sum\left[\frac{w\left(F_{o}^{2}-F_{C}^{2}\right)^{2}}{n-p}\right]^{2}\right.$ where $\mathrm{n}$ is the number of reflections and $\mathrm{p}$ is the total number of parameters refined. ${ }^{\mathrm{b}} R_{2}=\sum\left\|F_{o}|-| F_{c}\right\| / \sum \| F_{o} \mid ; w R_{2}=\left[\sum\left[\frac{w\left(F_{o}^{2}-F_{C}^{2}\right)^{2}}{\sum\left[w\left(F_{o}^{2}\right)^{2}\right.}\right]\right]^{\frac{1}{2}}$ 
Table S2 | Crystal data and structure refinement for $\mathbf{2}$.

\begin{tabular}{|c|c|}
\hline Empirical formula & $\mathrm{C}_{36} \mathrm{H}_{32} \mathrm{~B}_{2} \mathrm{~F}_{8} \mathrm{~N}_{8} \mathrm{Ni}$ \\
\hline Formula weight & 809.02 \\
\hline Temperature & $100.22 \mathrm{~K}$ \\
\hline Wavelength & 0.71073 \\
\hline Crystal system & Orthorhombic \\
\hline Space group & Pbca \\
\hline \multirow[t]{3}{*}{ Unit Cell Dimensions } & $\mathrm{a}=12.1939(10) \AA, \alpha=90^{\circ}$ \\
\hline & $\mathrm{b}=13.8696(11) \AA, \beta=90^{\circ}$ \\
\hline & $\mathrm{c}=21.4210(18) \AA, \gamma=90^{\circ}$ \\
\hline Volume & $3622.8(5) \AA^{3}$ \\
\hline Z & 4 \\
\hline Density (calculated) & $1.483 \mathrm{~g} / \mathrm{cm}^{3}$ \\
\hline Absorption coefficient & $0.617 \mathrm{~mm}^{-1}$ \\
\hline $\mathrm{F}_{000}$ & 1656.0 \\
\hline Crystal Color & Orange \\
\hline Crystal size & $0.353 \times 0.274 \times 0.213 \mathrm{~mm}^{3}$ \\
\hline$\theta$ range & 6.682 to $77.88^{\circ}$ \\
\hline \multirow[t]{3}{*}{ Index ranges } & $-21 \leq h \leq 21$ \\
\hline & $-24 \leq k \leq 24$ \\
\hline & $-37 \leq l \leq 37$ \\
\hline Reflections collected & 249076 \\
\hline Independent reflections & $10476\left[\mathrm{R}_{\text {int }}=0.0598, \mathrm{R}_{\text {sigma }}=0.0210\right]$ \\
\hline Completeness to $\theta=38.94^{\circ}$ & $99.8 \%$ \\
\hline Absorption correction & Multi-scan \\
\hline Maximum and minimum transmission & 0.7476 and 0.6984 \\
\hline Data/restraints/parameters & $10476 / 0 / 251$ \\
\hline Goodness-of-fit on $\mathrm{F}^{2}$ & 1.024 \\
\hline Final $R$ indexes $[\mathrm{I}>=2 \sigma(\mathrm{I})]$ & $\mathrm{R}_{1}=03.54 \%, \mathrm{wR}_{2}=9.42 \%$ \\
\hline Final $\mathrm{R}$ indexes [all data] & $\mathrm{R}_{1}=4.56 \%, \mathrm{wR}_{2}=10.15 \%$ \\
\hline Largest diff. peak and hole & 1.13 and -0.75 e. $\AA^{-3}$ \\
\hline
\end{tabular}

${ }^{\mathrm{a}} G O F=\left[\sum\left[\frac{w\left(F_{o}^{2}-F_{C}^{2}\right)^{2}}{n-p}\right]^{2}\right.$ where $\mathrm{n}$ is the number of reflections and $\mathrm{p}$ is the total number of parameters refined. ${ }^{\mathrm{b}} R_{2}=\sum\left\|F_{o}|-| F_{c}\right\| / \sum \| F_{o} \mid ; w R_{2}=\left[\sum\left[\frac{w\left(F_{o}^{2}-F_{C}^{2}\right)^{2}}{\sum\left[w\left(F_{o}^{2}\right)^{2}\right.}\right]\right]^{\frac{1}{2}}$ 
Table S3 | Spin-spin $\left(T_{\mathrm{m}}\right)$ and spin-lattice $\left(T_{1}\right)$ relaxation times for $\mathbf{1}$.

\begin{tabular}{cccccc} 
& \multicolumn{2}{c}{$1.53 \mathrm{~T}$} & & \multicolumn{2}{c}{$3.00 \mathrm{~T}$} \\
\cline { 2 - 3 } \cline { 5 - 6 } $\begin{array}{c}\text { Temperature } \\
(\mathrm{K})\end{array}$ & $T_{\mathrm{m}}(\mu \mathrm{s})$ & $T_{1}(\mu \mathrm{s})$ & & $T_{\mathrm{m}}(\mu \mathrm{s})$ & $T_{1}(\mu \mathrm{s})$ \\
\hline 5 & $1.15(2)$ & $11.2(3)$ & & $0.506(3)$ & $12.0(3)$ \\
7 & $0.82(1)$ & $7.4(5)$ & & $0.354(4)$ & $5.1(3)$ \\
10 & $0.63(1)$ & $4.0(2)$ & & $0.244(6)$ & $2.7(1)$ \\
12 & $0.544(8)$ & $2.8(1)$ & & $0.204(5)$ & $2.7(2)$ \\
15 & $0.370(8)$ & $1.94(8)$ & & $0.073(8)$ & - \\
17 & $0.320(8)$ & $0.94(7)$ & & - & - \\
20 & $0.252(6)$ & - & & - & - \\
\hline
\end{tabular}


Table S4 | Spin-spin $\left(T_{\mathrm{m}}\right)$ and spin-lattice $\left(T_{1}\right)$ relaxation times for 2.

\begin{tabular}{|c|c|c|c|c|}
\hline \multirow[b]{2}{*}{$\begin{array}{c}\text { Temperature } \\
(\mathrm{K})\end{array}$} & \multicolumn{2}{|c|}{$0.00 \mathrm{~T}$} & \multicolumn{2}{|c|}{$0.69 \mathrm{~T}$} \\
\hline & $T_{\mathrm{m}}(\mu \mathrm{s})$ & $T_{1}(\mu \mathrm{s})$ & $T_{\mathrm{m}}(\mu \mathrm{s})$ & $T_{1}(\mu \mathrm{s})$ \\
\hline 5 & $0.564(5)$ & $11.2(2)$ & $1.59(2)$ & $12.5(7)$ \\
\hline 7 & $0.463(6)$ & $9.7(5)$ & $0.74(2)$ & $2.2(1)$ \\
\hline 10 & $0.331(3)$ & $4.9(1)$ & - & - \\
\hline 12 & $0.309(5)$ & $4.3(2)$ & - & - \\
\hline \multirow[t]{2}{*}{15} & $0.247(9)$ & $2.9(2)$ & - & - \\
\hline & \multicolumn{2}{|c|}{$3.00 \mathrm{~T}$} & \multicolumn{2}{|c|}{$6.00 \mathrm{~T}$} \\
\hline $\begin{array}{c}\text { Temperature } \\
(\mathrm{K})\end{array}$ & $T_{\mathrm{m}}(\mu \mathrm{s})$ & $T_{1}(\mu \mathrm{s})$ & $T_{\mathrm{m}}(\mu \mathrm{s})$ & $T_{1}(\mu \mathrm{s})$ \\
\hline 5 & $0.683(8)$ & $4.6(1)$ & $0.98(2)$ & $10.3(6)$ \\
\hline 7 & $0.58(1)$ & $3.3(1)$ & $0.68(2)$ & $2.46(6)$ \\
\hline
\end{tabular}


Table S5 | Summary of spin Hamiltonian parameters for $\mathbf{1}$ and $\mathbf{2}$ determined by simulating cw-EPR spectra.

\begin{tabular}{ccc}
\hline & $\mathbf{1}$ & $\mathbf{2}$ \\
\hline$g_{\mathrm{x}}$ & 2.140 & 2.160 \\
$\mathrm{~g}_{\mathrm{y}}$ & 2.100 & 2.150 \\
$g_{\mathrm{z}}$ & 2.182 & 2.140 \\
$A_{\mathrm{x}}\left({ }^{14} \mathrm{~N}\right)(\mathrm{MHz})$ & 3.2 & 7.0 \\
$A_{\mathrm{y}}\left({ }^{14} \mathrm{~N}\right)(\mathrm{MHz})$ & 3.2 & 4.0 \\
$A_{\mathrm{z}}\left({ }^{14} \mathrm{~N}\right)(\mathrm{MHz})$ & 3.8 & 4.0 \\
$A_{\mathrm{x}}$ strain $(\mathrm{MHz})$ & - & 8.0 \\
$A_{\mathrm{y}}$ strain $(\mathrm{MHz})$ & 2.0 & 6.0 \\
$A_{\mathrm{z}}$ strain $(\mathrm{MHz})$ & 5.0 & 8.0 \\
$D\left(\mathrm{~cm}^{-1}\right)$ & +0.90 & +2.70 \\
$|E|\left(\mathrm{cm}^{-1}\right)$ & 0.20 & 0.10 \\
\hline
\end{tabular}



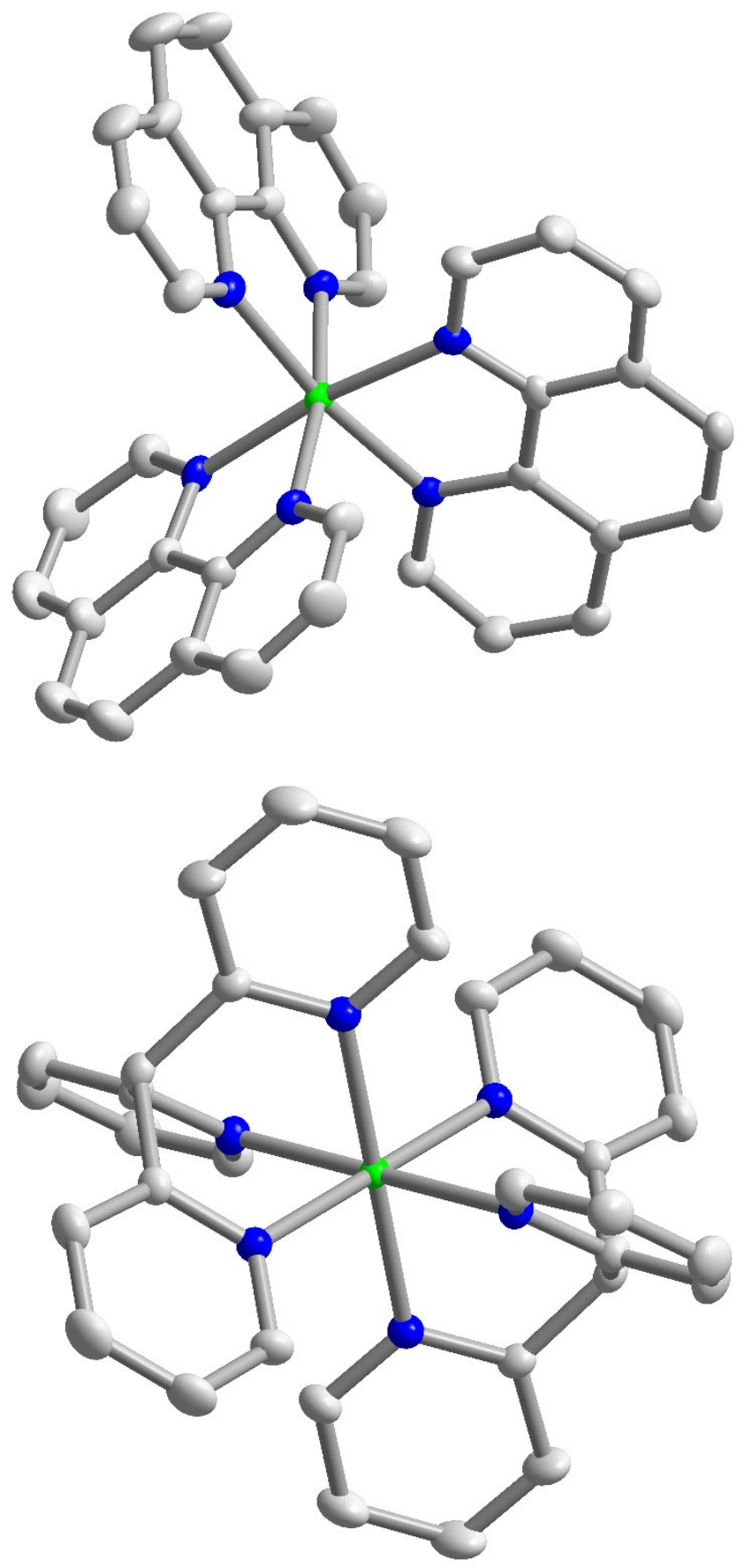

Figure S1 | Thermal ellipsoid plots of $\mathbf{1}$ (top) and $\mathbf{2}$ (bottom), depicted at the 70\% probability level. Gray, blue, and green spheres are carbon, nitrogen, and nickel atoms, respectively. Counterions and solvent molecules have been omitted for clarity. 

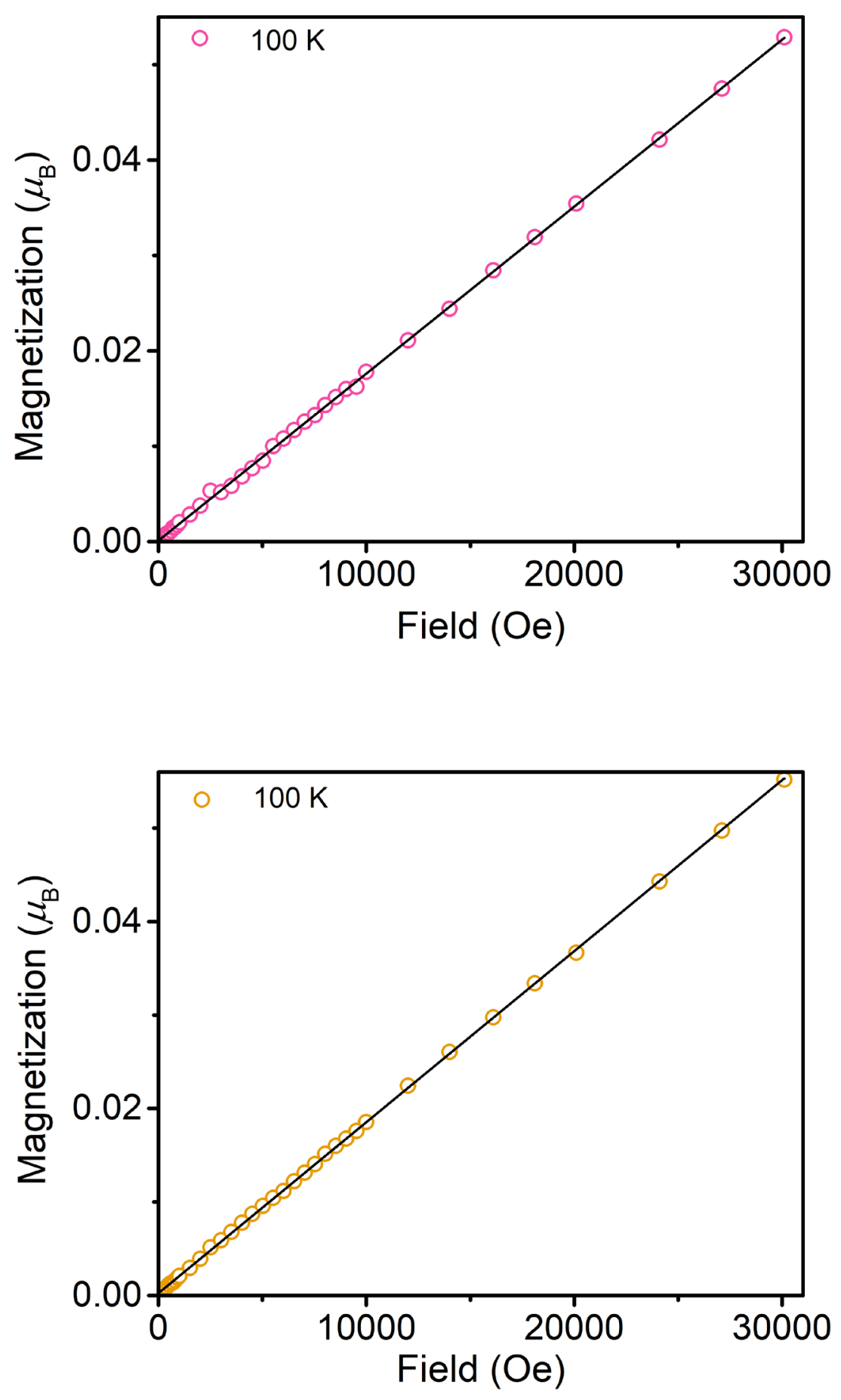

Figure S2 | Variable-field magnetization of polycrystalline samples of 1 (top) and 2 (bottom) restrained under eicosane acquired at $100 \mathrm{~K}$. The black line is a linear fit of the data illustrating the absence of ferromagnetic impurities. 

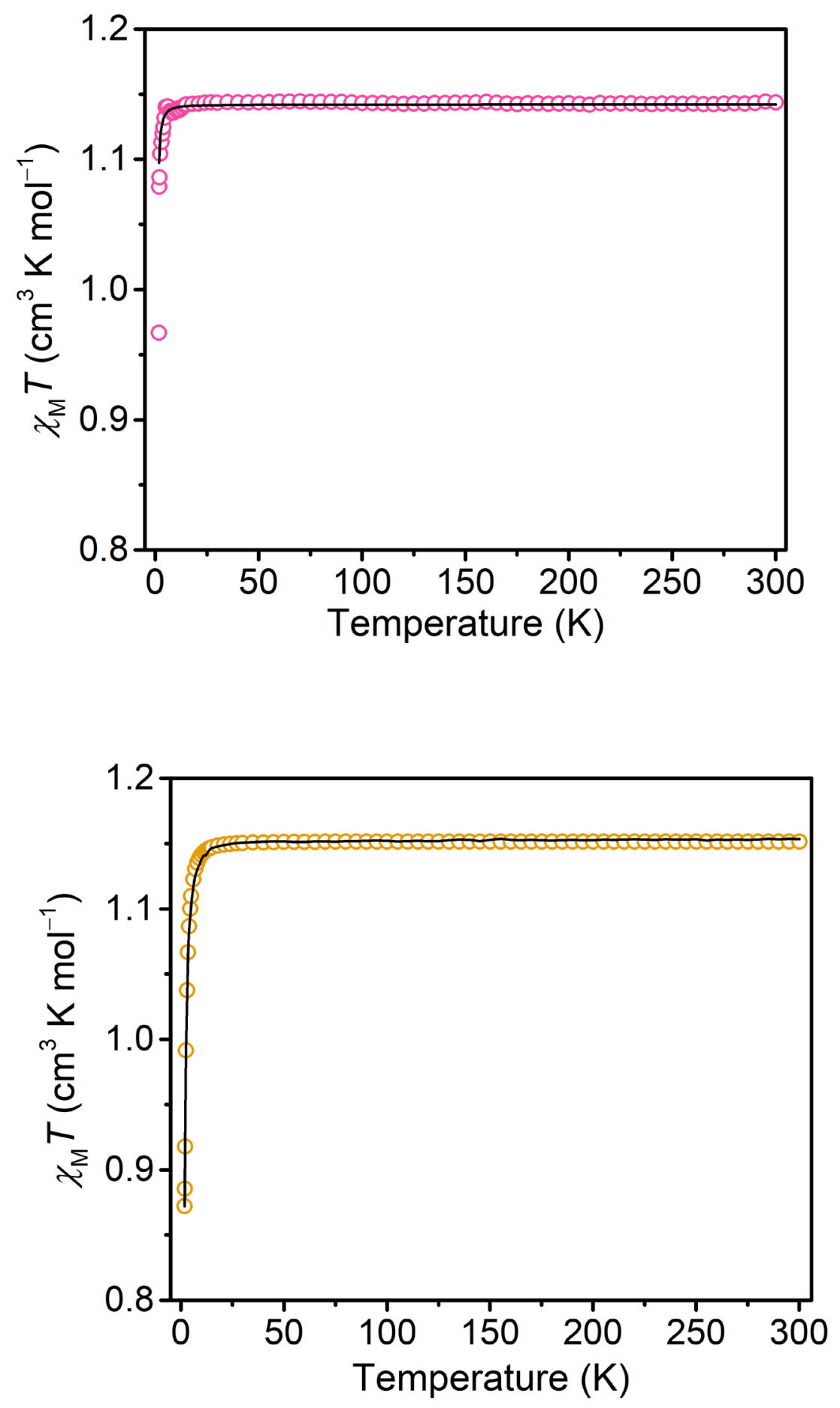

Figure S3 | Variable-temperature dc magnetic susceptibility data for $\mathbf{1}$ (top) and $\mathbf{2}$ (bottom) collected from $1.8 \mathrm{~K}$ to $300 \mathrm{~K}$ under a de field of $0.5 \mathrm{~T}$. The black lines represent the simulations obtained from the best fits to the data using the spin Hamiltonian $\hat{H}=\left[D \hat{S}_{\mathrm{z}}{ }^{2}-S(S+1) / 3\right]+E\left(\hat{S}_{\mathrm{x}}{ }^{2}-\hat{S}_{\mathrm{y}}{ }^{2}\right)+g \mu_{\mathrm{B}} \mathbf{S H}$ in DAVE 2.0. 

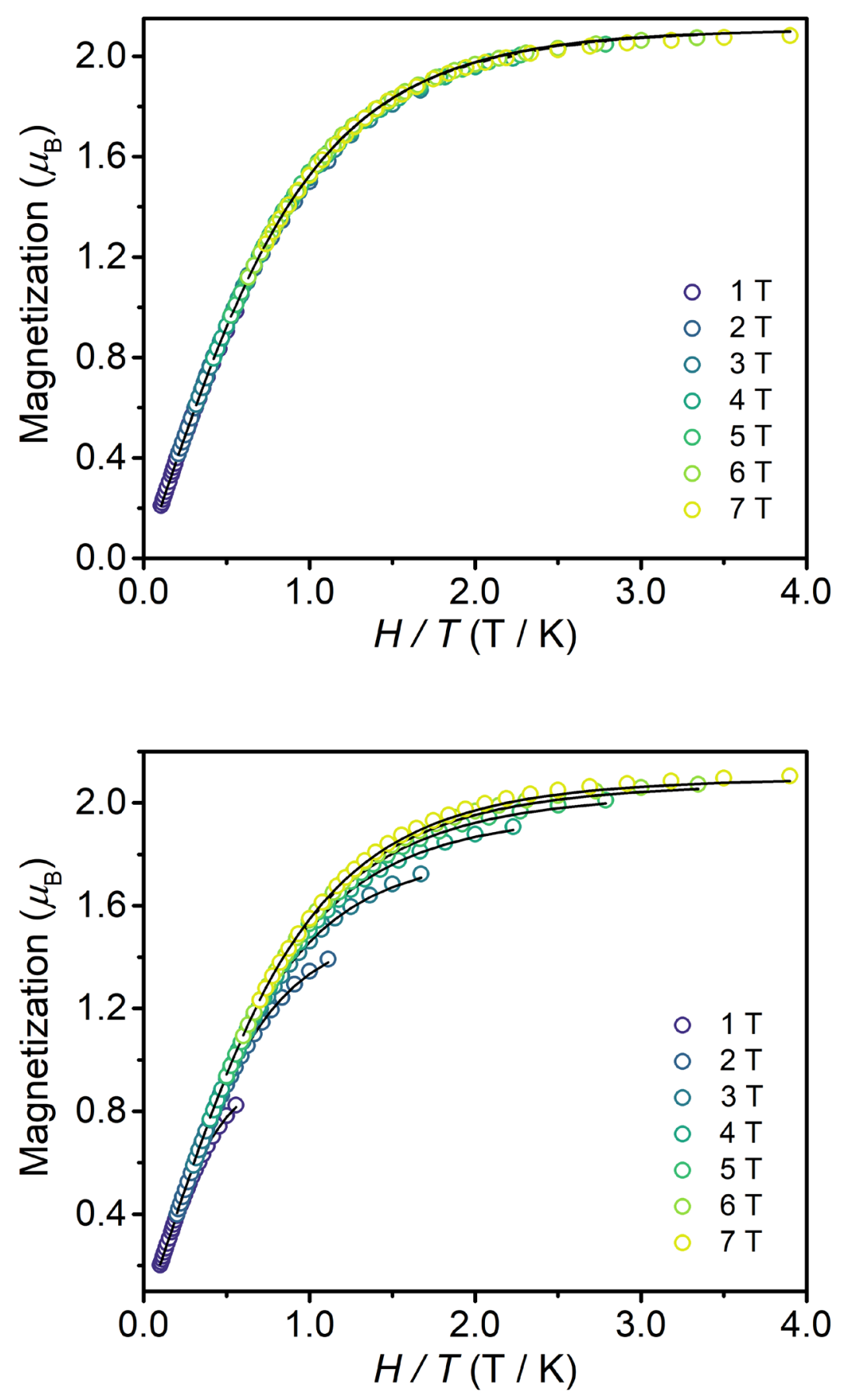

Figure S4 | Variable-temperature, variable-field magnetization data for $\mathbf{1}$ (top) and $\mathbf{2}$ (bottom) collected between 1.8 and $10 \mathrm{~K}$ from 1 to $7 \mathrm{~T}$ in $1 \mathrm{~T}$ increments. The black lines are simulations to the magnetization data using the spin Hamiltonian $\hat{H}=\left[D \hat{S}_{\mathrm{z}}^{2}-S(S+1) / 3\right]+E\left(\hat{S}_{\mathrm{x}}{ }^{2}-\hat{S}_{\mathrm{y}}{ }^{2}\right)+g \mu_{\mathrm{B}} \boldsymbol{S H}$ and magnetic parameters extracted from cw-EPR. Magnetic parameters for 1: $g_{\mathrm{x}}=2.140, g_{\mathrm{y}}=2.100, g_{\mathrm{z}}=2.182, D=+0.90 \mathrm{~cm}^{-1},|E|$ $=0.20 \mathrm{~cm}^{-1}$. Magnetic parameters for 2: $g_{\mathrm{x}}=2.160, g_{\mathrm{y}}=2.150, g_{\mathrm{z}}=2.140, D=+2.70 \mathrm{~cm}^{-1},|E|=0.10 \mathrm{~cm}^{-}$ 1 . 

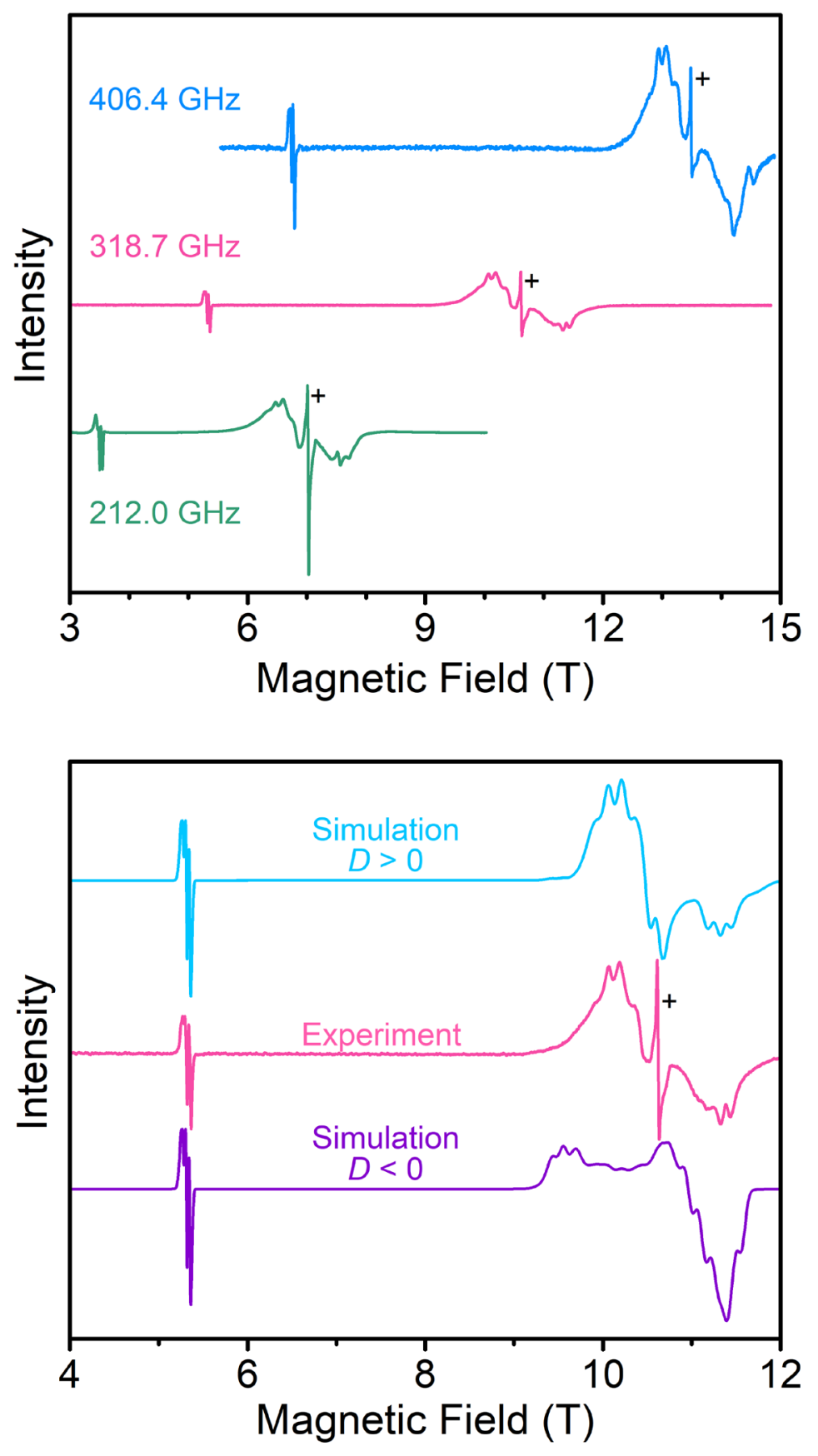

Figure S5 | (top) High frequency EPR spectra for 1 at $5 \mathrm{~K}$. (bottom) Best spectral simulations of the 318.7 $\mathrm{GHz}$ spectrum at $5 \mathrm{Kwith}$ negative and positive $D$ values. Parameters for $D>0$ simulation: $g_{\mathrm{x}}=2.140, g_{\mathrm{y}}$ $=2.100, g_{\mathrm{z}}=2.182, A_{\mathrm{x}}\left({ }^{14} \mathrm{~N}\right)=3.2 \mathrm{MHz}, A_{\mathrm{y}}\left({ }^{14} \mathrm{~N}\right)=3.2 \mathrm{MHz}, A_{\mathrm{z}}\left({ }^{14} \mathrm{~N}\right)=3.8 \mathrm{MHz}, D=+0.90 \mathrm{~cm}^{-1},|E|=0.20$ $\mathrm{cm}^{-1}$. Parameters for $D<0$ simulation: $g_{\mathrm{x}}=2.140, g_{\mathrm{y}}=2.100, g_{\mathrm{z}}=2.182, A_{\mathrm{x}}\left({ }^{14} \mathrm{~N}\right)=3.2 \mathrm{MHz}, A_{\mathrm{y}}\left({ }^{14} \mathrm{~N}\right)=3.2$ $\mathrm{MHz}, A_{\mathrm{z}}\left({ }^{14} \mathrm{~N}\right)=3.8 \mathrm{MHz}, D=-0.90 \mathrm{~cm}^{-1},|E|=0.20 \mathrm{~cm}^{-1}$. No change in the spectral simulation is observed by changing the sign of $E$; therefore we were unable to determine the sign. The plus sign denotes the double quantum transition. 


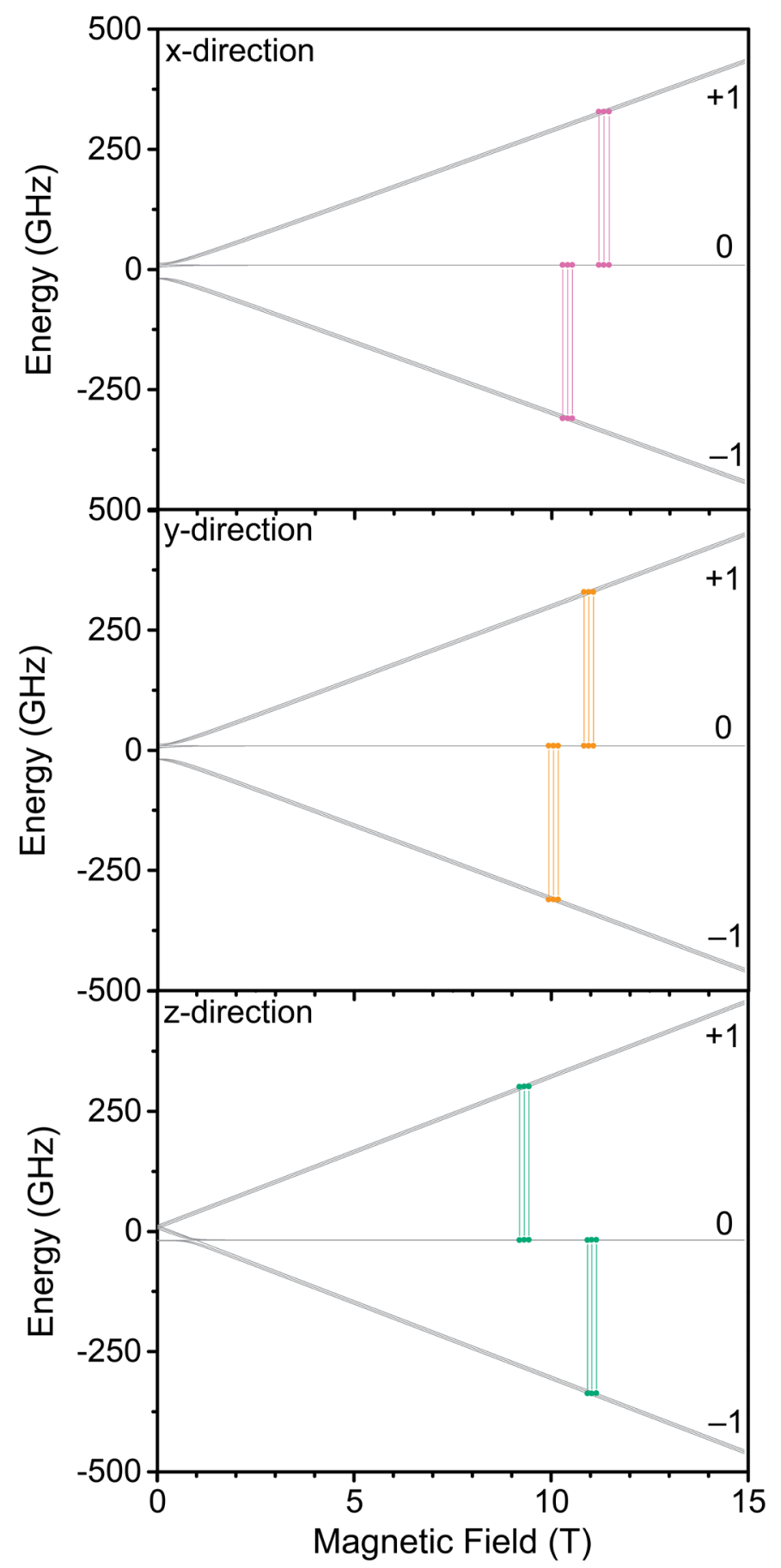

Figure S6 | Zeeman diagrams for 318.7 GHz EPR simulations of 1. The Zeeman plots are simulated with the external magnetic field oriented along the $x-, y-$, and $z$-molecular axes (top, middle, bottom, respectively) highlighting the transitions (vertical lines) observed in the spectrum. The low-field transitions are formally forbidden yet are observed owing to a random orientation of B1 in the spectrometer. The -1 , 0 and $+1 M_{S}$ sublevels are labelled in the high field regimes. The spin Hamiltonian parameters $g, D$, and $E$ used for these simulations are given in the manuscript. 

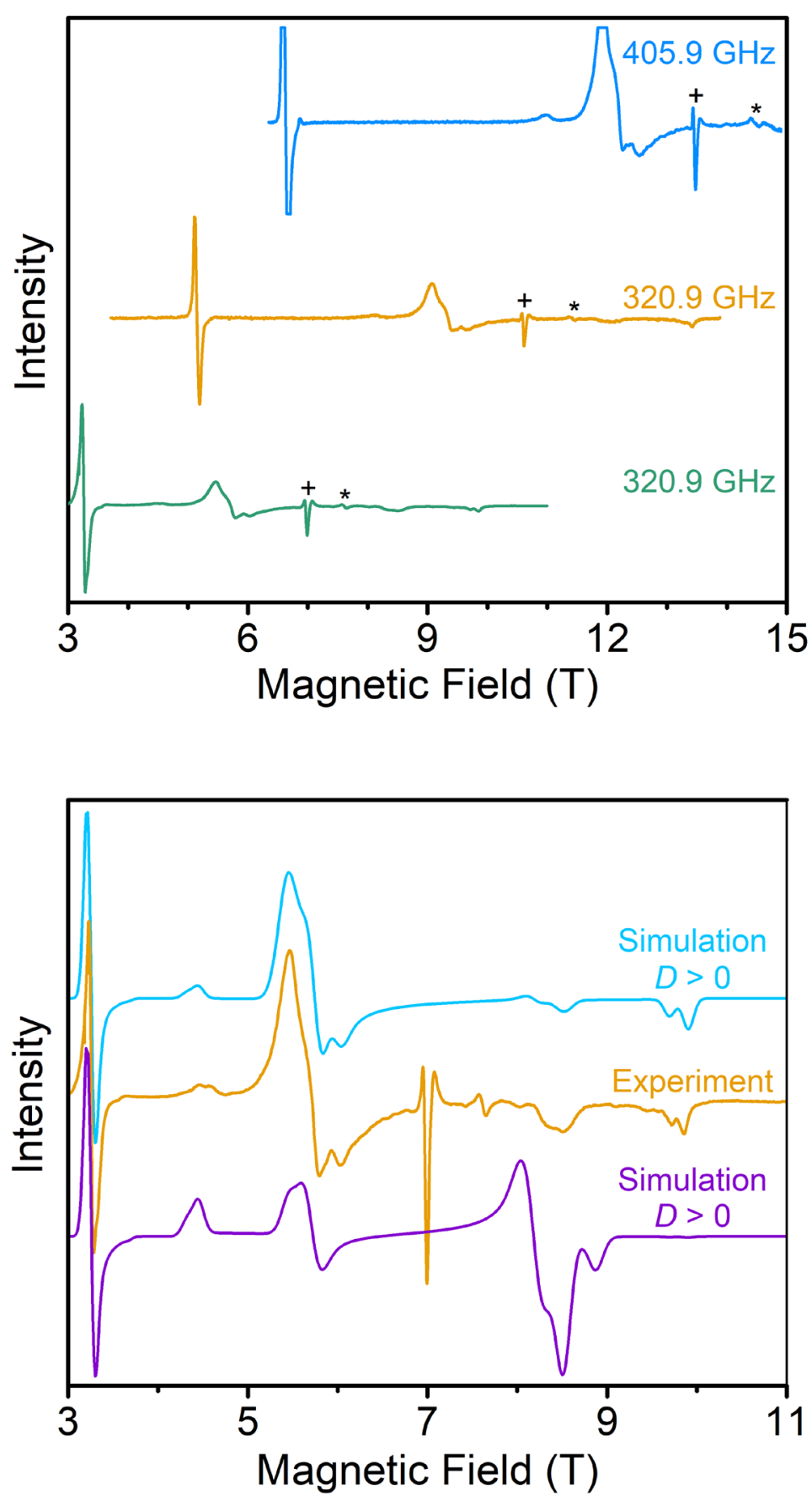

Figure S7 | (top) High-frequency EPR spectra for 2 at 5 K. (bottom) Best spectral simulations of the 213.0 $\mathrm{GHz}$ spectrum at $5 \mathrm{~K}$ with negative and positive $D$ values. Parameters for $D>0$ simulation: $g_{\mathrm{x}}=2.160, g_{\mathrm{y}}$ $=2.150, g_{\mathrm{z}}=2.140, A_{\mathrm{x}}\left({ }^{14} \mathrm{~N}\right)=7.0 \mathrm{MHz}, A_{\mathrm{y}}\left({ }^{14} \mathrm{~N}\right)=4.0 \mathrm{MHz}, A_{\mathrm{z}}\left({ }^{14} \mathrm{~N}\right)=4.0 \mathrm{MHz}, D=+2.70 \mathrm{~cm}^{-1},|E|=$ $0.10 \mathrm{~cm}^{-1}$. Parameters for $D<0$ simulation $g_{\mathrm{x}}=2.160, g_{\mathrm{y}}=2.150, g_{\mathrm{z}}=2.140, A_{\mathrm{x}}\left({ }^{14} \mathrm{~N}\right)=7.0 \mathrm{MHz}, A_{\mathrm{y}}\left({ }^{14} \mathrm{~N}\right)$ $=4.0 \mathrm{MHz}, A_{\mathrm{z}}\left({ }^{14} \mathrm{~N}\right)=4.0 \mathrm{MHz}, D=-2.70 \mathrm{~cm}^{-1},|E|=0.10 \mathrm{~cm}^{-1}$. No change in the spectral simulation is observed by changing the sign of $E$; thus the sign could not be determined. The plus sign denotes the double quantum transition. The asterisk denotes a $g=2$ impurity. 


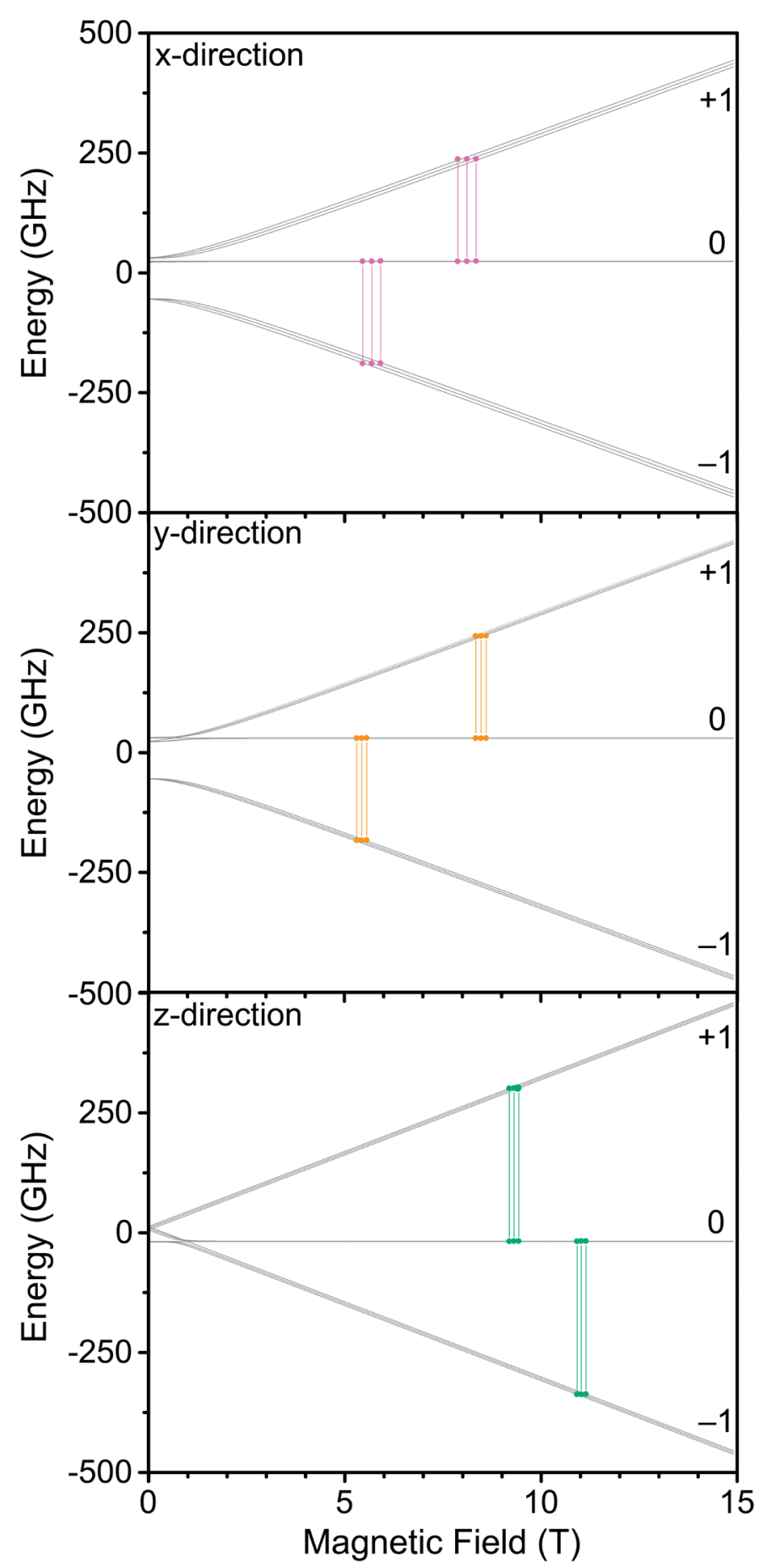

Figure S8 | Zeeman diagrams for 213.0 GHz EPR simulations of 2. The Zeeman plots are simulated with the magnetic field oriented along the $x-, y-$, and $z$-molecular axes (top, middle, bottom, respectively) highlighting the transitions (vertical lines) observed in the spectrum. The low-field transitions are formally forbidden yet are observed owing to a random orientation of B1 in the spectrometer. The $-1,0$ and $+1 M_{S}$ sublevels are labelled in the high field regime. The spin Hamiltonian parameters $g, D$, and $E$ used for these simulations are given in the manuscript. 

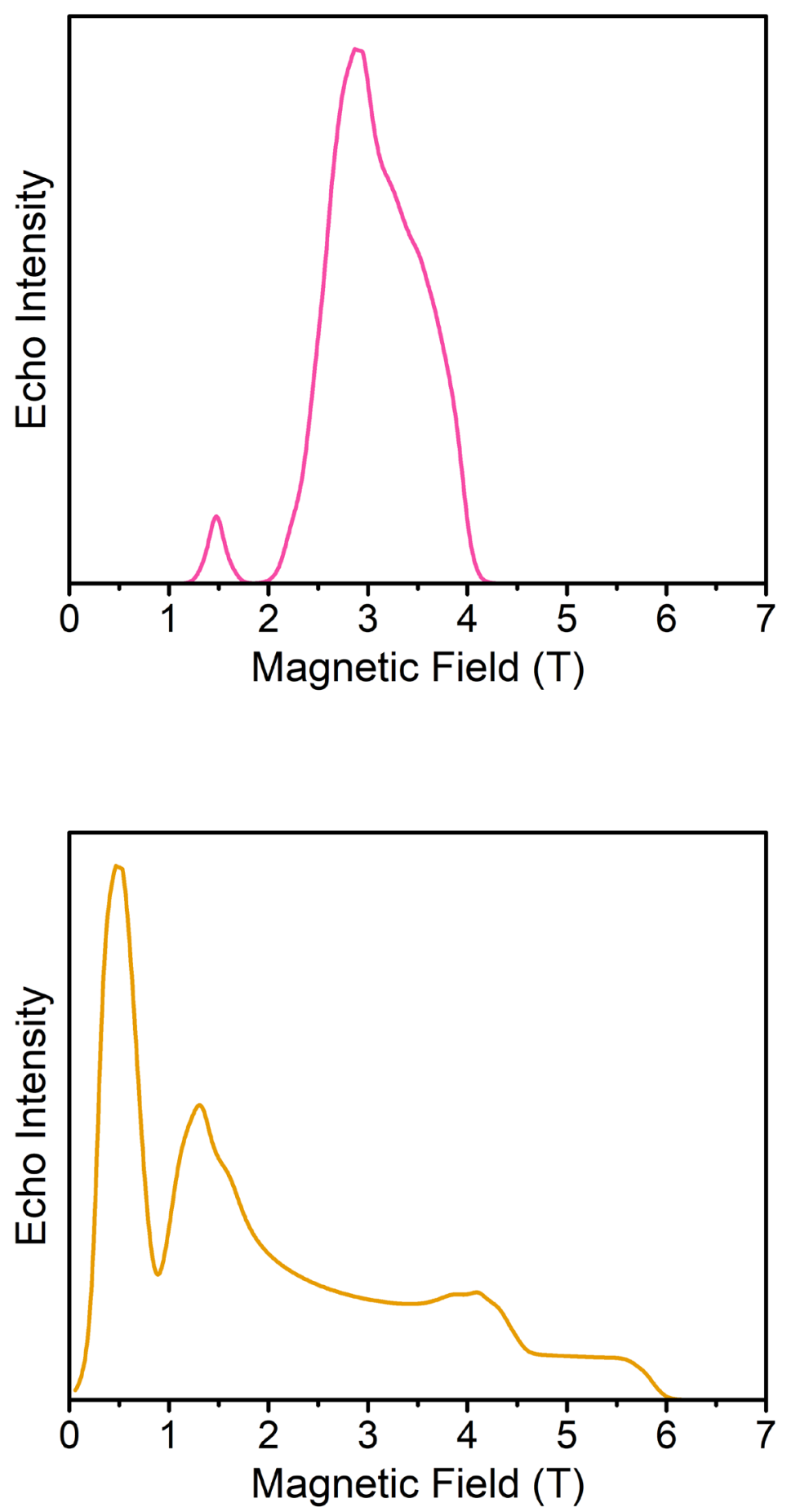

Figure S9 | Calculated absorptive cw mode of 1 and 2 at $94 \mathrm{GHz}$, using the cw-EPR parameters from Figures S5 and S7, respectively. 

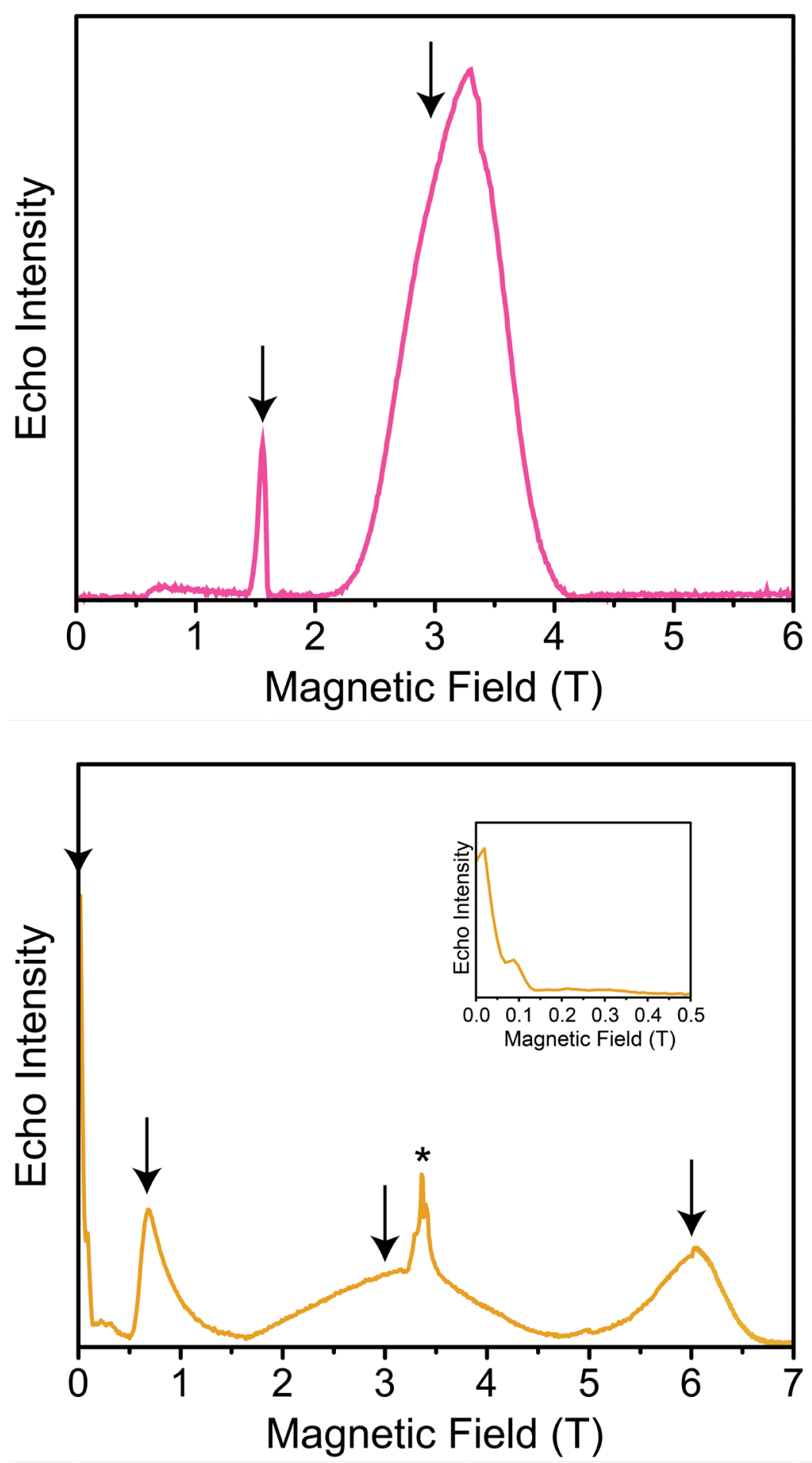

Figure S10 | Echo-detected field-swept spectrum of $\mathbf{1}$ (top) and $\mathbf{2}$ (bottom) at $5 \mathrm{~K}$, collected at $94 \mathrm{GHz}$. The arrows indicate magnetic fields where $T_{1}$ and $T_{\mathrm{m}}$ were measured for $\mathbf{1}$ and $\mathbf{2}$. The asterisk denotes a $g$ $=2$ impurity. 


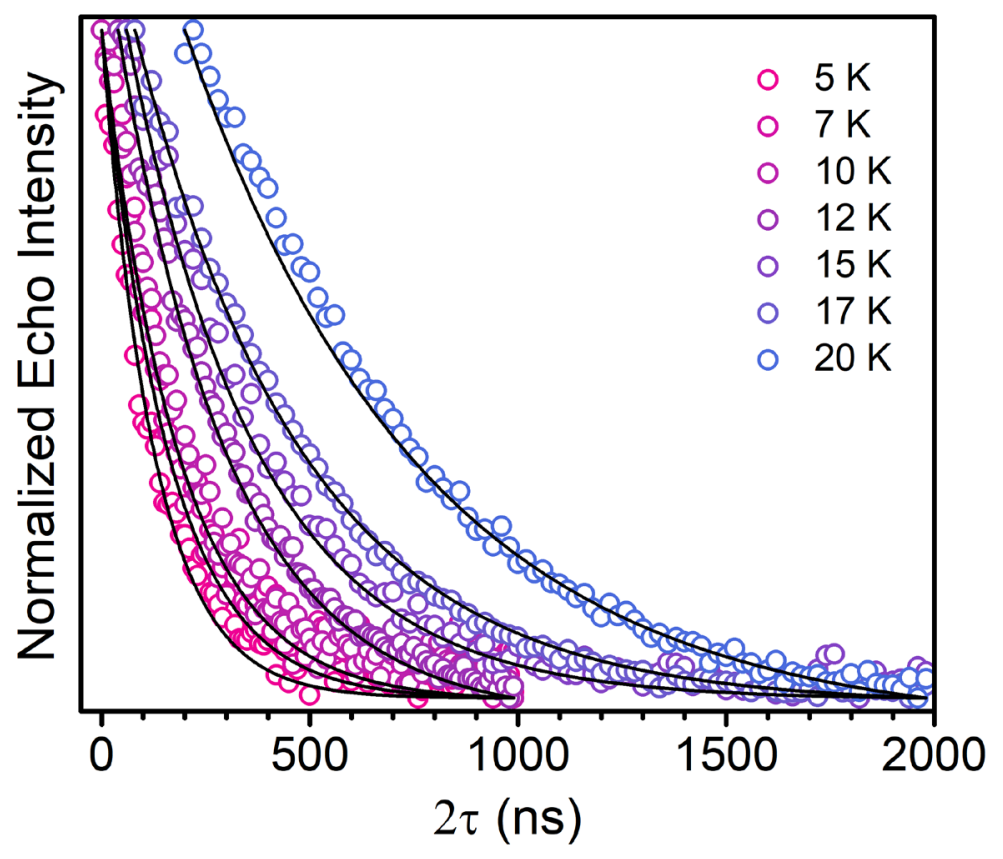

Figure S11 | Hahn-echo decay curves for 1 at $1.53 \mathrm{~T}$ from $5 \mathrm{~K}$ to $20 \mathrm{~K}$. The echo decay intensities (circles) were fit (black lines) using a mono-exponential function to yield the $T_{\mathrm{m}}$ times given in Table 3 . 


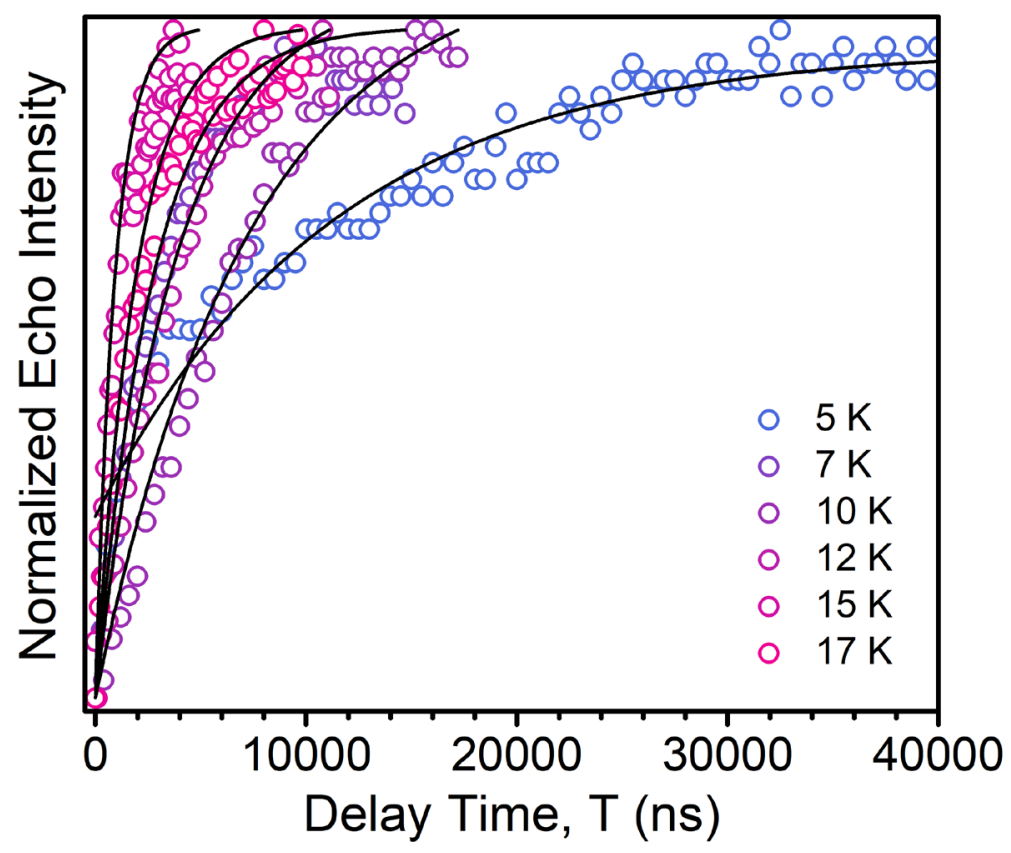

Figure S12 | Saturation-recovery data for 1 at $1.53 \mathrm{~T}$ from $5 \mathrm{~K}$ to $17 \mathrm{~K}$. The saturation recovery data (circles) were fit (black lines) using a monoexponential recovery function to yield the $T_{1}$ times given in Table S3. 


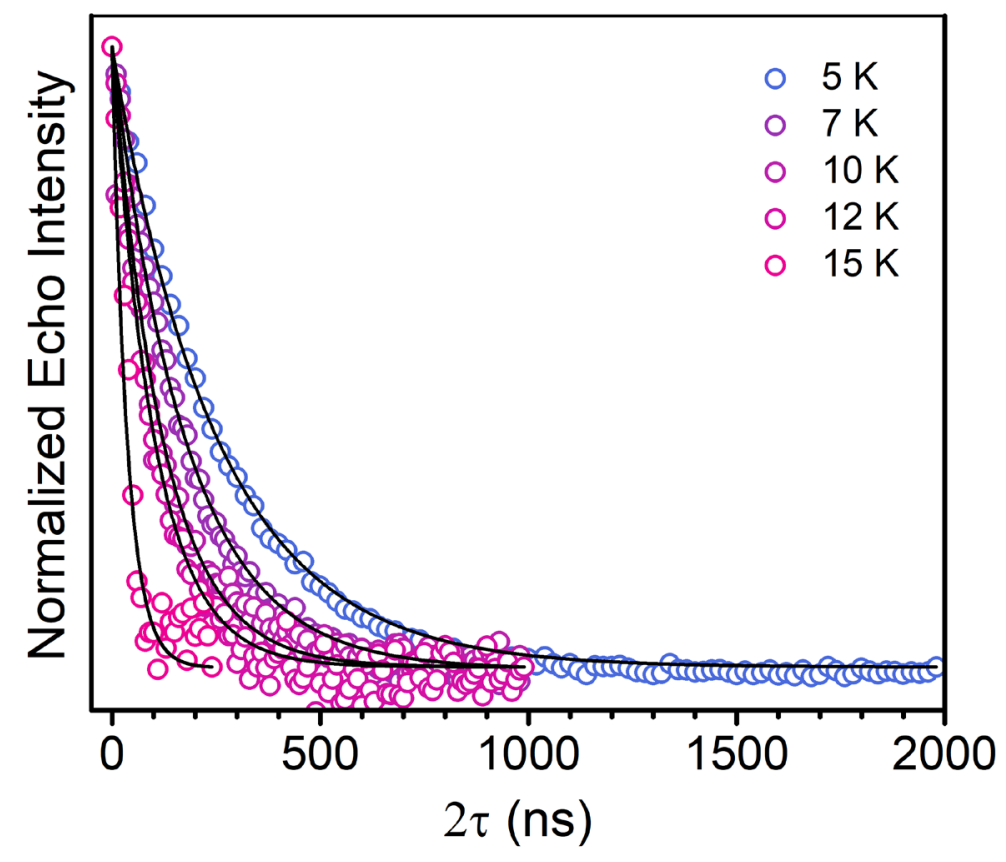

Figure S13 | Hahn-echo decay curves for 1 at $3.00 \mathrm{~T}$ from $5 \mathrm{~K}$ to $15 \mathrm{~K}$. The decay intensities (circles) were fit (black lines) using a mono-exponential decay function to yield the $T_{\mathrm{m}}$ times given in Table S3. 


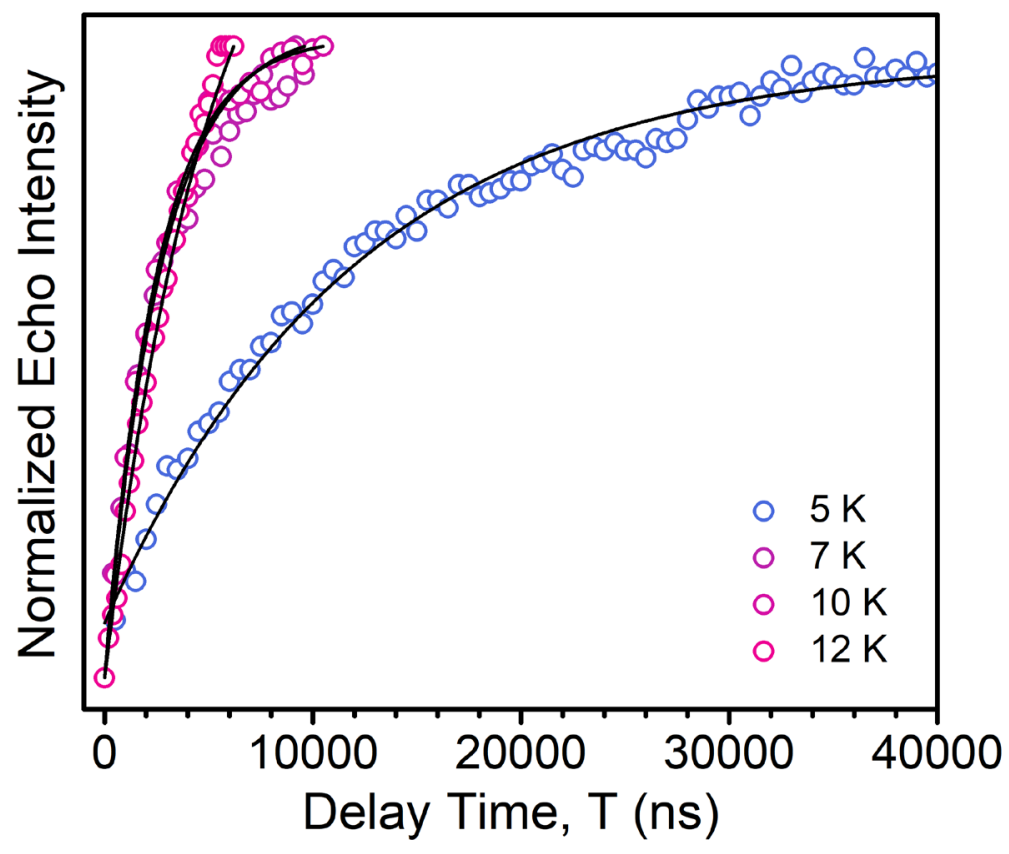

Figure S14 | Saturation-recovery data for 1 at $3.00 \mathrm{~T}$ from $5 \mathrm{~K}$ to $15 \mathrm{~K}$. The saturation recovery data (circles) were fit (black lines) using a mono-exponential recovery function to yield the $T_{1}$ times given in Table S3. 


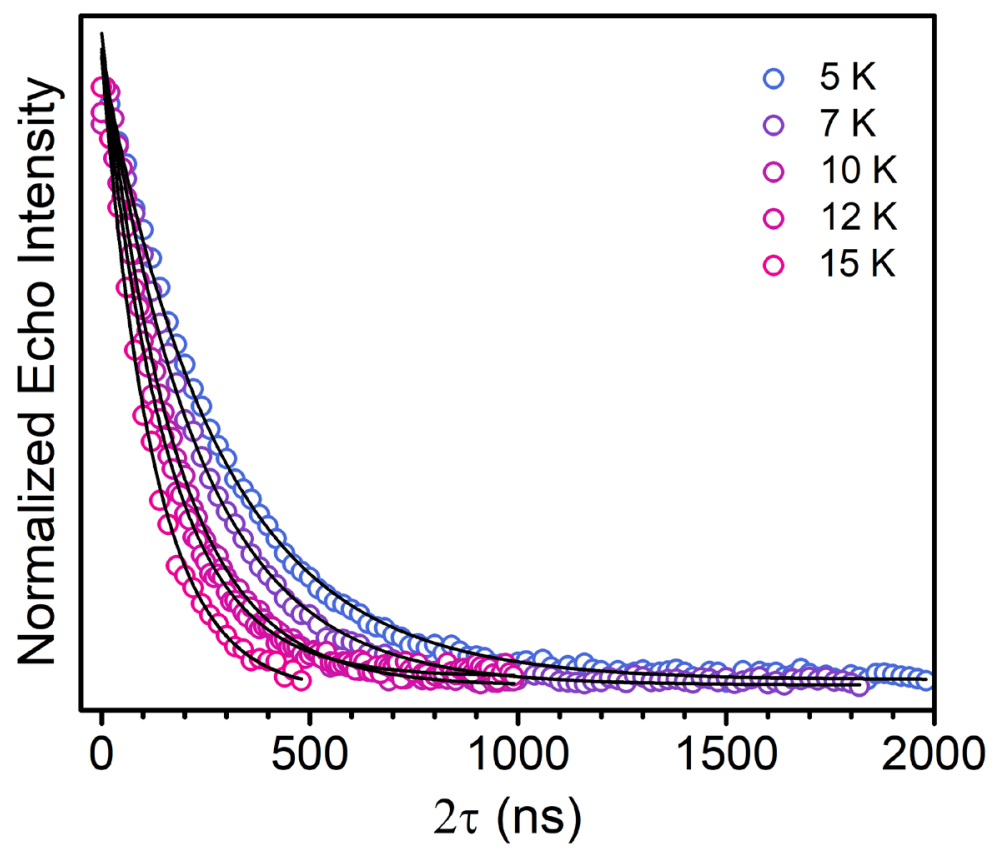

Figure S15 | Hahn-echo decay curves for 2 at $0.00 \mathrm{~T}$ from $5 \mathrm{~K}$ to $15 \mathrm{~K}$. The decay intensities (circles) were fit (black lines) using a mono-exponential decay function to yield $T_{\mathrm{m}}$ times given in Table $\mathrm{S} 4$. 


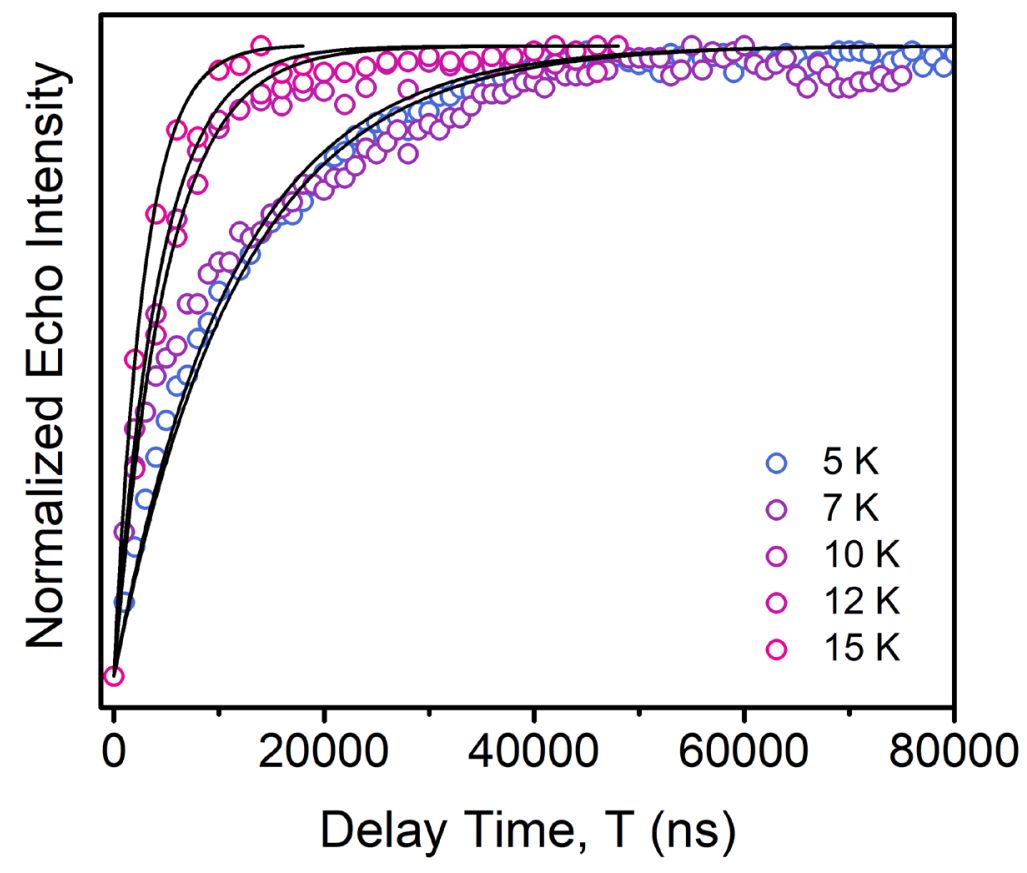

Figure S16 | Saturation-recovery data for 2 at $0.00 \mathrm{~T}$ from $5 \mathrm{~K}$ to $15 \mathrm{~K}$. The saturation-recovery data (circles) were fit (black lines) using a mono-exponential recovery function to the $T_{1}$ times given in Table S4. 


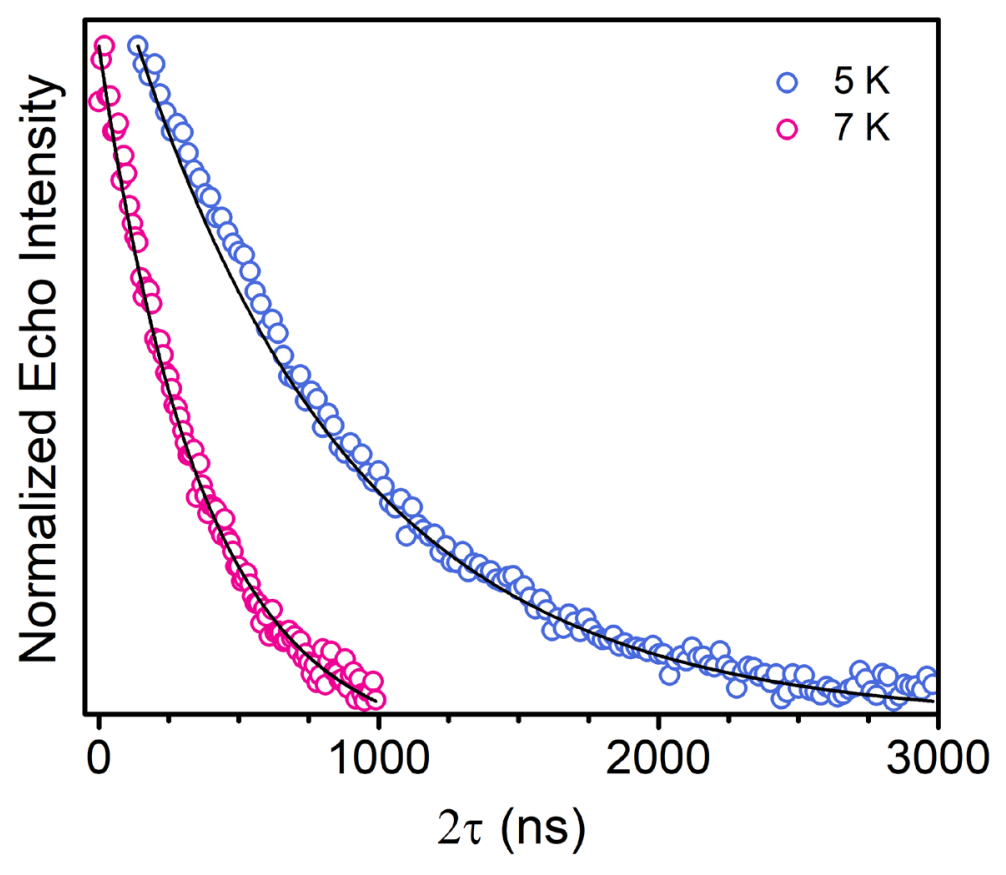

Figure S17 | Hahn-echo decay curves for 2 at $0.69 \mathrm{~T}$ at $5 \mathrm{~K}$ and $7 \mathrm{~K}$. The decay intensities (circles) were fit (black lines) using a mono-exponential decay function to yield the $T_{\mathrm{m}}$ times given in Table $\mathrm{S} 4$. 


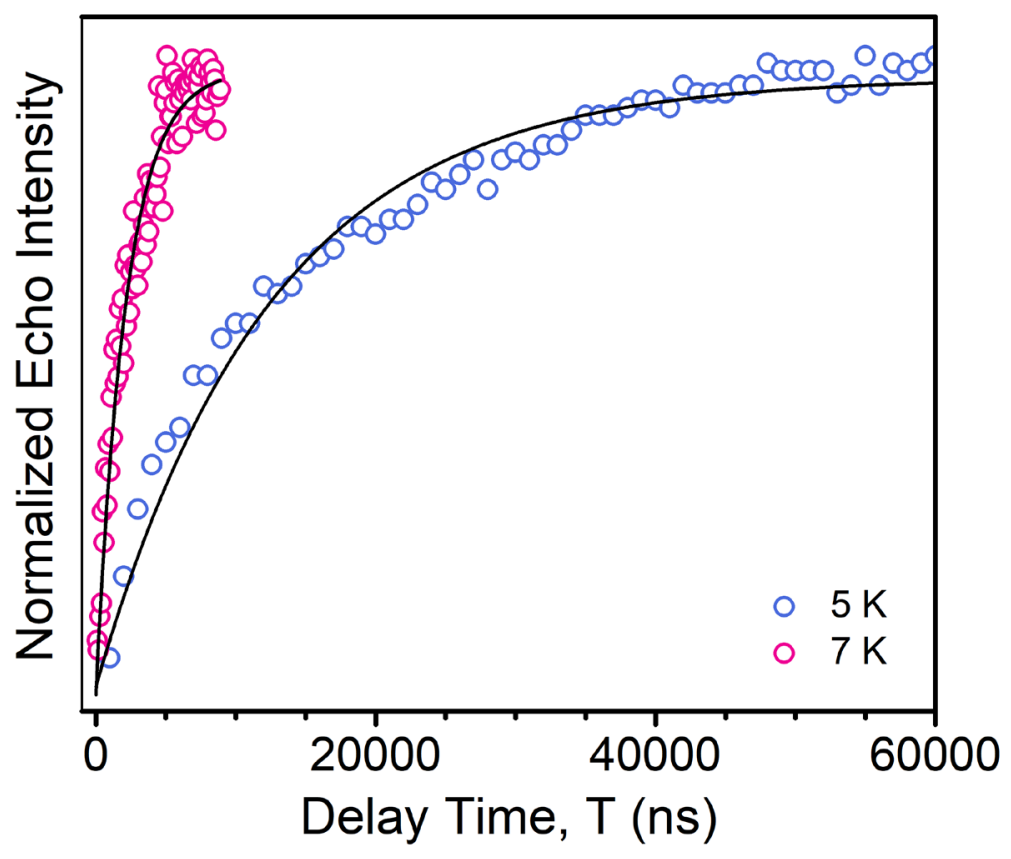

Figure S18 | Saturation-recovery data for 2 at $0.69 \mathrm{~T}$ at $5 \mathrm{~K}$ and $7 \mathrm{~K}$. The saturation-recovery data (circles) were fit (black lines) using a mono-exponential recovery function to yield the $T_{1}$ times given in Table S4. 


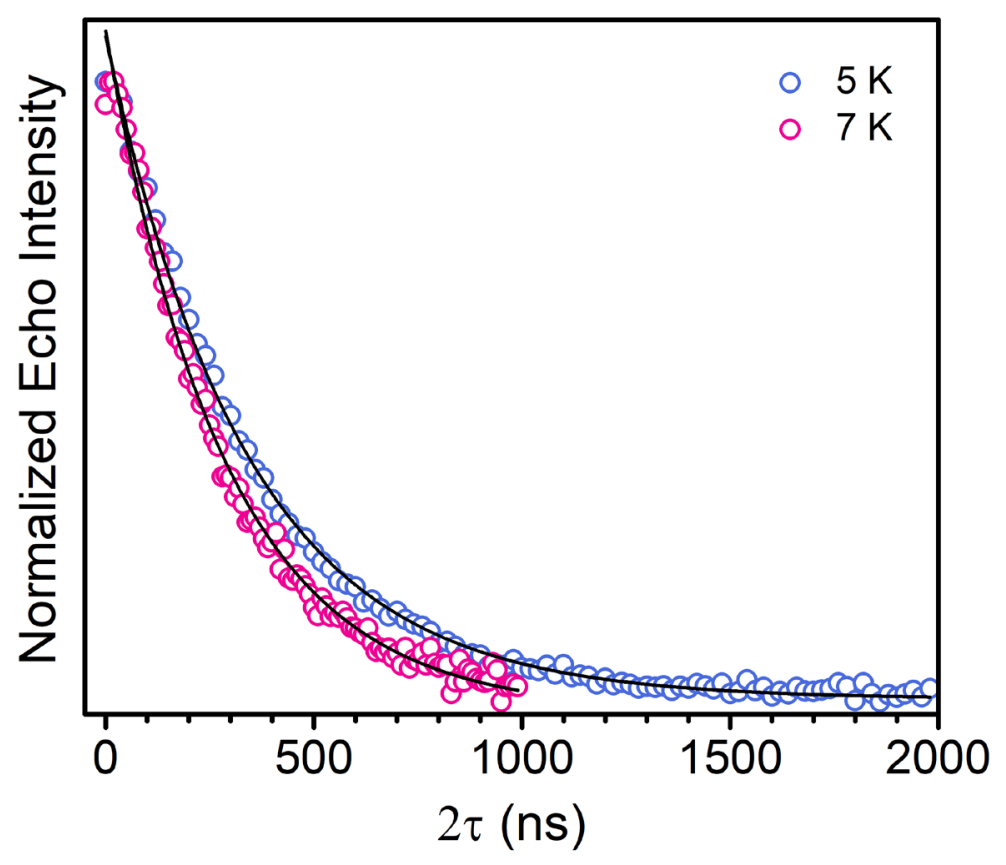

Figure S19 | Hahn-echo decay curves for 2 at $3.00 \mathrm{~T}$ at $5 \mathrm{~K}$ and $7 \mathrm{~K}$. The decay intensities (circles) were fit (black lines) using a mono-exponential decay function to yield the $T_{\mathrm{m}}$ times given in Table S4. 


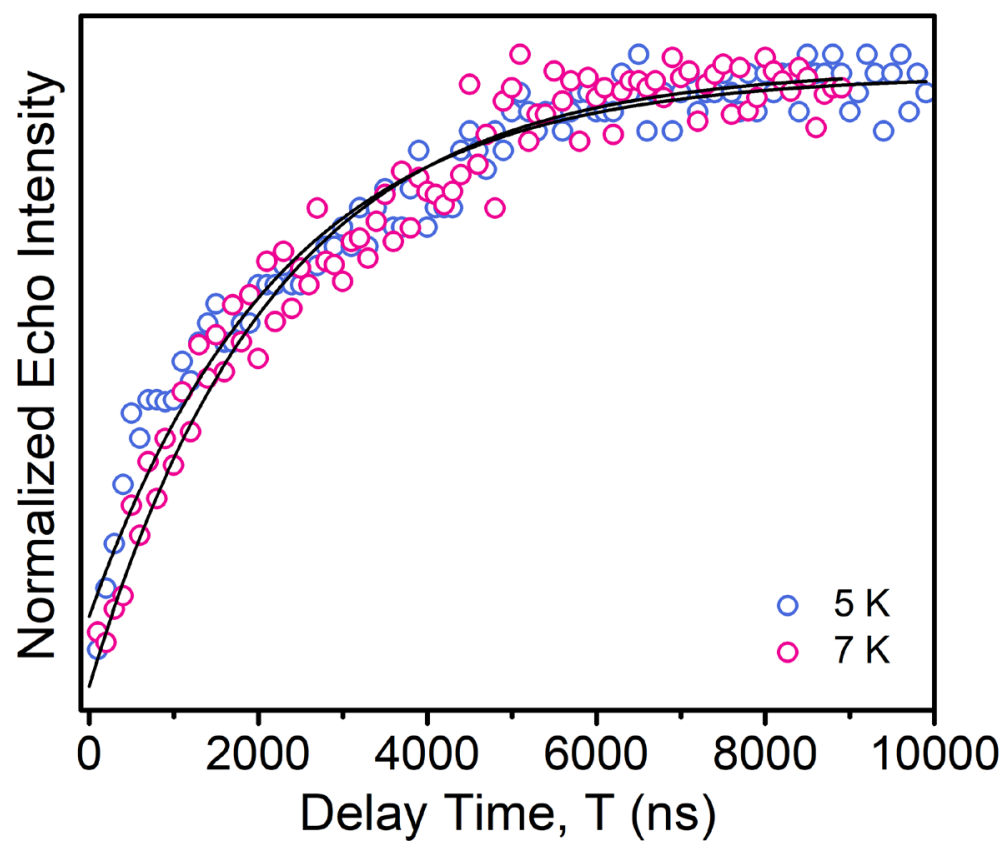

Figure S20 | Saturation-recovery data for 2 at $3.00 \mathrm{~T}$ at $5 \mathrm{~K}$ and $7 \mathrm{~K}$. The saturation-recovery data (circles) were fit (black lines) using a mono-exponential recovery function to yield the $T_{1}$ times given in Table S4. 


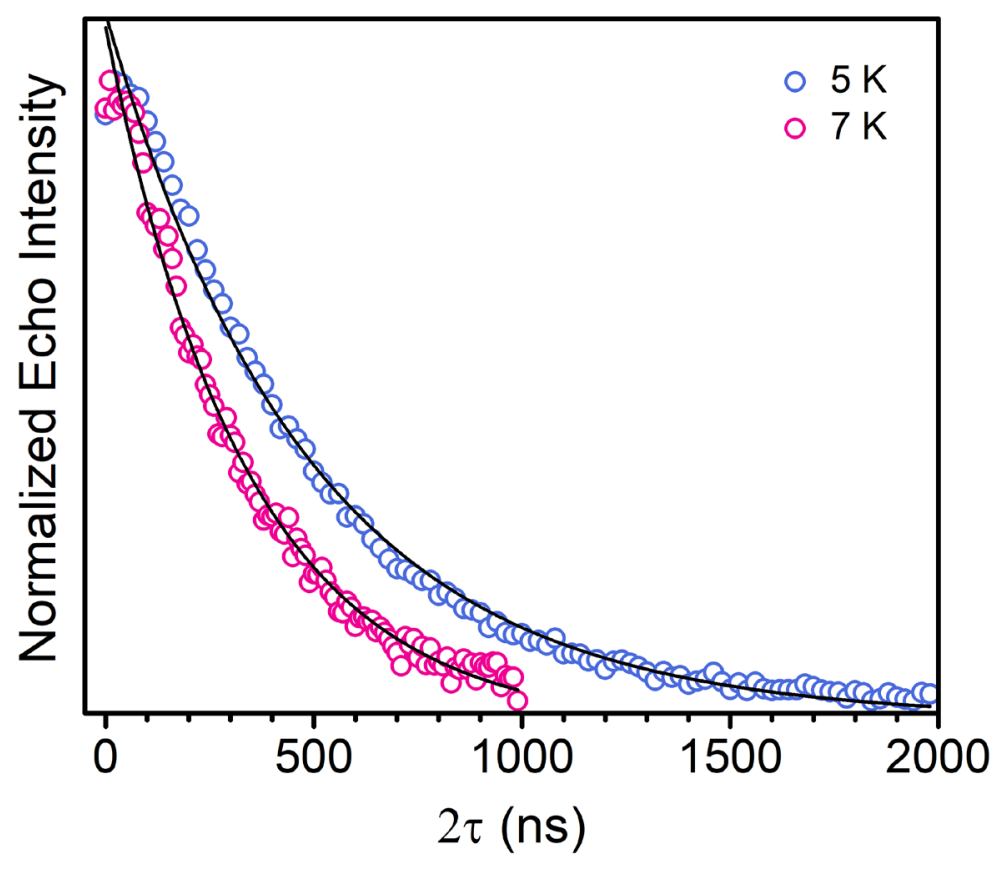

Figure S21 | Hahn-echo decay curves for 2 at $6.00 \mathrm{~T}$ at $5 \mathrm{~K}$ and $7 \mathrm{~K}$. The decay intensities (circles) were fit (black lines) using a mono-exponential decay function to yield the $T_{\mathrm{m}}$ times given in Table S4. 


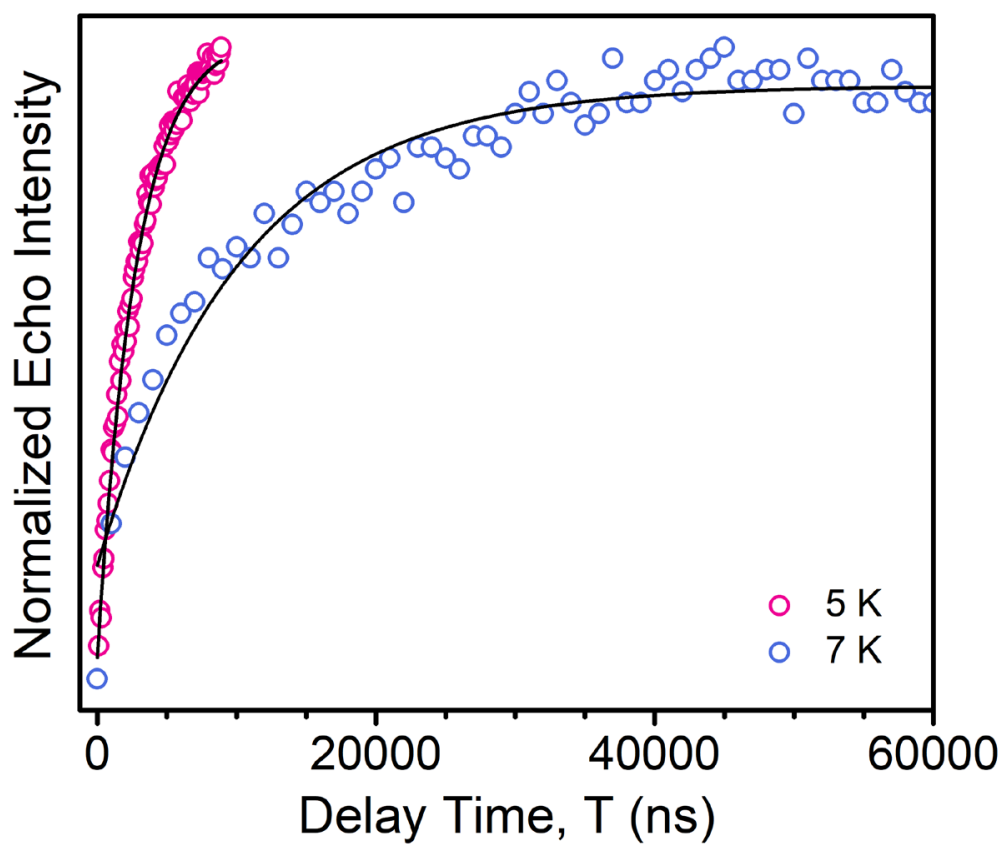

Figure S22 | Saturation-recovery data for 2 at $6.00 \mathrm{~T}$ at $5 \mathrm{~K}$ and $7 \mathrm{~K}$. The saturation-recovery data (circles) were fit (black lines) using a mono-exponential recovery function to yield the $T_{1}$ times given in Table S4. 


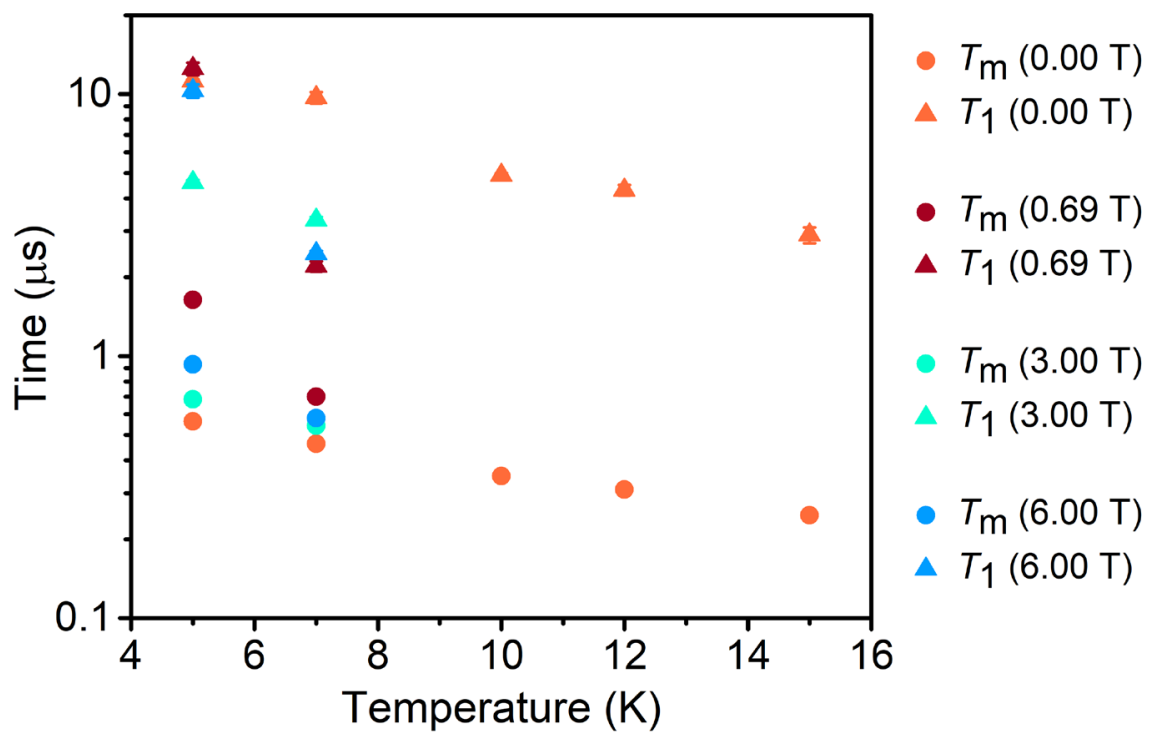

Figure S23 $\mid T_{1}$ and $T_{\mathrm{m}}$ values for 1 at $0.00 \mathrm{~T}$ (orange), $0.69 \mathrm{~T}$ (dark maroon), $3.00 \mathrm{~T}$ (aquamarine), and 6.00 (light blue). 


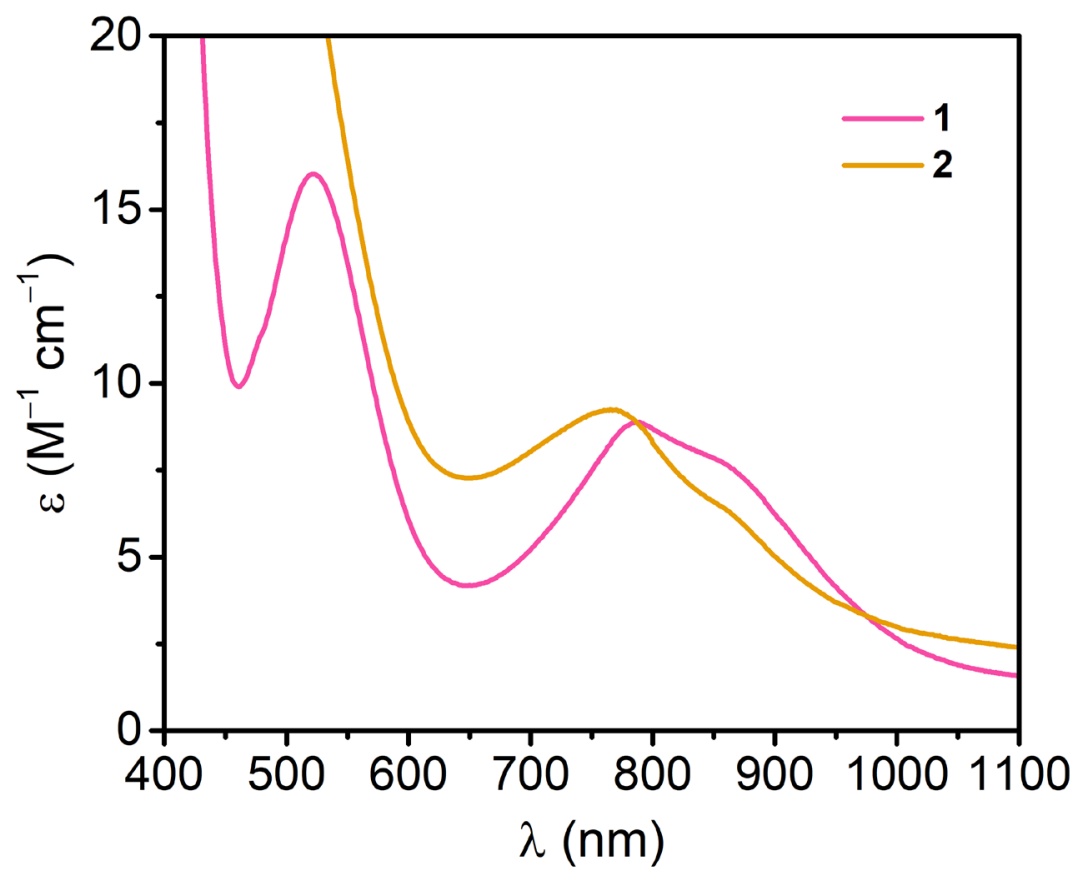

Figure S24 | Electronic absorption (UV-vis-NIR) spectra collected in $\mathrm{MeCN}$ solutions at room temperature for 1 and 2. 


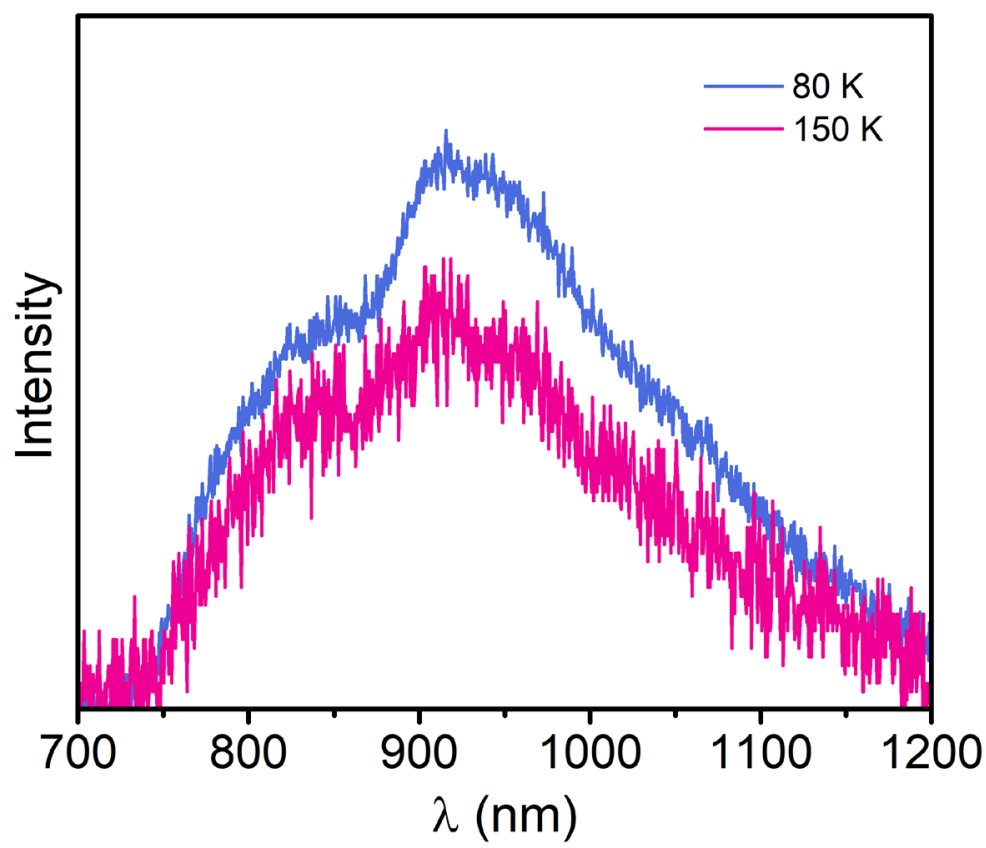

Figure S25 | Photoluminescence spectrum of 1 collected with solid-state powders at $80 \mathrm{~K}$ and $150 \mathrm{~K}$, with a $450 \mathrm{~nm}$ excitation source and $665 \mathrm{~nm}$ and $780 \mathrm{~nm}$ long pass filters employed. 


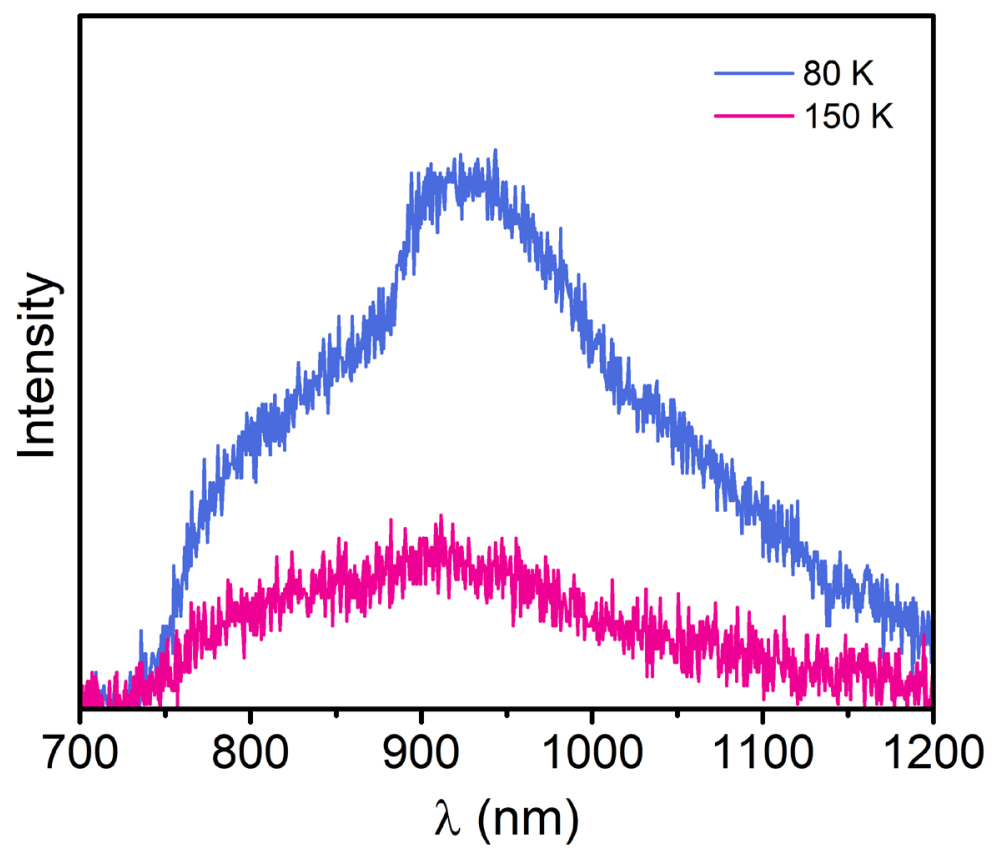

Figure S26 | Photoluminescence spectrum of 2 collected with solid-state powders at $80 \mathrm{~K}$ and $150 \mathrm{~K}$, with a $450 \mathrm{~nm}$ excitation source and $665 \mathrm{~nm}$ and $780 \mathrm{~nm}$ long pass filters employed. 


\section{References}

(1) Maleckis, A.; Kampf, J. W.; Sanford, M. S. A detailed study of acetate-assisted C-H activation at palladium(IV) centers. J. Am. Chem. Soc. 2013, 13, 6618-6625.

(2) Vander Griend, D. A.; Bediako, D. K.; DeVries, M. J.; DeJong, N. A.; Heeringa, L. P. Detailed Spectroscopic, Thermodynamic, and Kinetic Characterization of Nickel(II) Complexes with 2,2'Bipyridine and 1,10-Phenanthroline Attained via Equilibrium-Restricted Factor Analysis. Inorg. Chem. 2008, 47, 656-662.

(3) Astley, T.; Hitchman, M. A.; Richard Keene, F.; Tiekink, E. R. T. Structural, Spectroscopic and Angular-Overlap Studies of Tripodal Pyridine Ligands with Nickel(II) and Zinc(II). J. Chem. Soc. - Dalt. Trans. 1996, 1845-1851.

(4) Bain, G. A.; Berry, J. F. Diamagnetic Corrections and Pascal's Constants. J. Chem. Educ. 2008, 85, $532-536$.

(5) APEX2, v. 2009; Bruker Analytical X-ray Systems, Inc.: Madison, WI, 2009.

(6) Sheldrick, G. M. SADABS, Version2.03; Bruker Analytical X-ray Systems, Inc.: Madison, WI, 2000.

(7) Sheldrick, G. M. SHELXTL, Version 6.12; Bruker Analytical X-ray Systems, Inc.: Madison, WI, 2000.

(8) Farrugia, L. J. WinGX Suite for Small-Molecule Single-Crystal Crystallography. J. Appl. Cryst. 1999, $32,837-838$.

(9) Hassan, A. K.; Pardi, L. A.; Krzystek, J.; Sienkiewicz, A.; Goy, P.; Rohrer, M.; Brunel, L.-C. Ultrawide Band Multifrequency High-Field EMR Technique: A Methodology for Increasing Spectroscopic Information. J. Magn. Reson. 2000, 142, 300-312.

(10) Stoll, S.; Schweiger, A. EasySpin, a Comprehensive Software Package for Spectral Simulation and Analysis in EPR. J. Magn. Reson. 2006, 178, 42-55.

(11) Cruickshank, P. A. S.; Bolton, D. R.; Robertson, D. A.; Hunter, R. I.; Wylde, R. J.; Smith, G. M. A Kilowatt Pulsed 94 GHz Electron Paramagnetic Resonance Spectrometer with High Concentration Sensitivity, High Instantaneous Bandwidth, and Low Dead Time. Rev. Sci. Instrum. 2009, 80, 103102. 